\title{
UK Renal Registry 19th Annual Report: Chapter 7 Haemoglobin, Ferritin and Erythropoietin amongst UK Adult Dialysis Patients in 2015: National and Centre-specific Analyses
}

\author{
Daniel Ford ${ }^{\mathrm{a}}$, Julie Gilg ${ }^{\mathrm{b}}$, Andrew J Williams ${ }^{\mathrm{c}}$ \\ a University Hospital Coventry and Warwickshire, Coventry, UK; ${ }^{\mathrm{b} U K}$ Renal Registry, Bristol, UK; ${ }^{\mathrm{c}}$ Morriston Hospital, \\ Swansea, UK
}

\section{Keywords}

Anaemia · Chronic kidney disease · Dialysis · End stage renal disease · Epidemiology · Erythropoietin · Erythropoiesis stimulating agent - European Best Practice Guidelines • Ferritin - Haemodialysis - Haemoglobin - NICE · Peritoneal dialysis · Renal Association

\section{Summary}

In the UK in 2015:

- The median haemoglobin $(\mathrm{Hb})$ of patients at the time of starting dialysis was $98 \mathrm{~g} / \mathrm{L}$ with $47 \%$ of patients having a $\mathrm{Hb} \geqslant 100 \mathrm{~g} / \mathrm{L}$.

- The median $\mathrm{Hb}$ in patients starting haemodialysis (HD) was $96 \mathrm{~g} / \mathrm{L}$ (IQR 87-105) and in patients starting peritoneal dialysis (PD) was $107 \mathrm{~g} / \mathrm{L}$ (IQR 98-116).

- At the start of dialysis $51 \%$ of patients presenting early had $\mathrm{Hb} \geqslant 100 \mathrm{~g} / \mathrm{L}$ compared with only $34 \%$ of patients presenting late.
- The median $\mathrm{Hb}$ of prevalent patients on $\mathrm{HD}$ was $110 \mathrm{~g} / \mathrm{L}$ (IQR 101-119).

- The median $\mathrm{Hb}$ of prevalent patients on PD was $112 \mathrm{~g} / \mathrm{L}$ (IQR 103-120).

- $79 \%$ of HD patients and $81 \%$ of PD patients had $\mathrm{Hb}$ $\geqslant 100 \mathrm{~g} / \mathrm{L}$.

- $59 \%$ of HD patients and $57 \%$ of PD patients had $\mathrm{Hb}$ $\geqslant 100$ and $\leqslant 120 \mathrm{~g} / \mathrm{L}$.

- The median serum ferritin in HD patients was $415 \mu \mathrm{g} / \mathrm{L}$ and $94 \%$ of HD patients had a ferritin $\geqslant 100 \mu \mathrm{g} / \mathrm{L}$.

- The median serum ferritin in PD patients was $295 \mu \mathrm{g} / \mathrm{L}$ and $88 \%$ of PD patients had a ferritin $\geqslant 100 \mu \mathrm{g} / \mathrm{L}$.

In England, Wales and Northern Ireland in 2015:

- The median erythropoiesis stimulating agent (ESA) dose in HD patients was 7,500 IU/week.

- The median ESA dose in PD patients was 4,000 IU/ week.

\section{KARGER}

Fax +4161306 1234 E-Mail karger@karger.com www.karger.com/nef
This article is licensed under the Creative Commons AttributionNonCommercial-NoDerivatives 4.0 International License (CC BYNC-ND) (http://www.karger.com/Services/OpenAccessLicense). Usage and distribution for commercial purposes as well as an distribution of modified material requires written permission.
Daniel Ford

UK Renal Registry, Southmead Hospital, Southmead Road,

Bristol, BS10 5NB, UK

Email: renalregistry@renalregistry.nhs.uk 


\section{Introduction}

Anaemia is a common feature of chronic kidney disease (CKD) and when untreated is strongly associated with poor outcomes resulting in increased hospitalisations and mortality. This chapter describes analyses of the management of anaemia in dialysis patients in the UK in 2015.

A number of clinical practice guidelines exist for the management of anaemia in patients with CKD. The Kidney Disease Improving Global Outcomes (KDIGO) Clinical Practice Guideline for Anemia in Chronic Kidney Disease was published in August 2012 [1]. Commentaries and position statements on this document were made by both the Kidney Disease Outcomes Quality Initiative (KDOQI), and the European Renal Best Practice Guidelines Group (ERBP) [2, 3]. The Renal Association Clinical Practice Guideline for Anaemia of CKD (5th edition) was published in 2010 with the 6th edition expected in 2017 [4]. The National Institute for Health and Care Excellence (NICE) Clinical Guideline on Chronic Kidney Disease: Managing Anaemia was published in June 2015, mid-way through the data collection period [5].

This chapter reports on the analyses of data items collected by the UK Renal Registry (UKRR) measured against the audit parameters set in the Renal Association Clinical Practice Guideline (5th edition) [4]. Table 7.1 lists the audit measures recommended in these guidelines alongside those parameters measured in this chapter and reasons for exclusion.

\section{Methods}

Most of the analyses in this chapter use the incident or prevalent renal replacement therapy (RRT) cohorts for 2015. Some analyses use data from earlier years. Haemoglobin levels are given in $\mathrm{g} / \mathrm{L}$ as the majority of UK laboratories have now switched to reporting using these units rather than $\mathrm{g} / \mathrm{dl}$.

Table 7.1. Summary of recommended Renal Association audit measures

RA audit measure

1. Proportion of CKD patients with eGFR $<30 \mathrm{ml} / \mathrm{min}$ by 4 variable MDRD method with an annual $\mathrm{Hb}$ level

2. Proportion of patients starting an ESA without prior measurement of serum ferritin and/or TSAT

3. Proportion of patients on renal replacement therapy with $\mathrm{Hb}$ level $<10$ who are not prescribed an ESA

4. Each renal unit should audit the type, route and frequency of administration and weekly dose of ESA prescribed

5. The proportion of CKD stage $4-5$ patients with $\mathrm{Hb} 10-12 \mathrm{~g} / \mathrm{dl}$

6. The proportion of patients treated with an ESA with $\mathrm{Hb}>12 \mathrm{~g} / \mathrm{dl}$

7. Each renal unit should monitor ESA dose adjustments

8. Proportion of patients with serum ferritin levels $<100 \mathrm{ng} / \mathrm{ml}$ at start of treatment with ESA

9. Proportion of pre-dialysis and PD patients receiving iron therapy; type: oral vs. parenteral

10. Proportion of $\mathrm{HD}$ patients receiving IV iron

11. Prevalence of resistance to ESA among renal replacement therapy patients

12. Proportion of HD patients who received a blood transfusion within the past year

Included in UKRR

annual report?

Reason for exclusion

No

No

Yes

UKRR reports the completeness of these data items

No

Yes

No UKRR does not collect this data

No

No

No

Yes

No Data held at NHS Blood and Transplant
Data not available for the period covered by this report UKRR does not know when all patients start ESA treatment. UKRR does not collect TSAT data

Data not available for the period covered by this report

UKRR does not know when all patients start ESA treatment

Data not available for the period covered by this report/poor data completeness

Poor data completeness 
The UKRR extracted quarterly data electronically from renal centres in England, Wales and Northern Ireland (E,W\&NI) taking the latest available result from each quarter. Data from Scotland were provided by the Scottish Renal Registry (SRR).

For the analyses of $\mathrm{Hb}$ for incident patients, those patients commencing RRT on PD or HD were included whilst those receiving a pre-emptive transplant were excluded. $\mathrm{Hb}$ measurements from after starting dialysis but still within the same quarter of the year were used. Therefore, depending on when in the quarter a patient started RRT the $\mathrm{Hb}$ data could be from zero to 90 days later. Due to possible deficiencies with extract routines it is possible that a small number of the values extracted electronically may actually be from before the person started dialysis. This problem will not occur for Scottish data. Patients who died within the first 90 days on treatment were excluded. Results are also shown with the cohort subdivided into early and late presenters (date first seen by a nephrologist, 90 or more days and less than 90 days before starting dialysis respectively). For these analyses only centres with at least $75 \%$ completeness of presentation time data were included.

For the analyses of prevalent dialysis patients those patients receiving dialysis on 31st December 2015 were included if they had been on the same modality of dialysis in the same centre for at least three months. In order to improve completeness, the last available measurement for each patient from the last two quarters was used for $\mathrm{Hb}$ and from the last three quarters for ferritin.

The completeness of data items was analysed at both centre and country level. All patients were included in analyses but centres with less than $50 \%$ completeness were excluded from the caterpillar and funnel plots showing centre level results. Centres providing relevant data from less than 10 patients were also excluded from the plots. The number preceding the centre name in the caterpillar plots is the percentage of patients who have data missing.

Summary statistics including minimum, maximum, interquartile ranges (IQR), averages (mean and median) and standard deviations were calculated. The median values and the IQRs are shown using caterpillar plots. The percentages achieving standards were also calculated and these are displayed using caterpillar plots with the percentages meeting the targets and 95\% confidence intervals (CIs) shown. Funnel plots show the distribution of the percentages meeting the targets and also whether any of the centres were significantly different from the average. Longitudinal analyses were performed to show overall changes in achievement of standards over time.

Erythropoietin data from the last quarter of 2015 were used to define which patients were receiving erythropoietin stimulating agents (ESAs). Scotland was excluded from this analysis as data about ESAs were only available for May (and average doses over the year were used here - see later). Each individual was defined as being on ESA if a drug type and/or a dose was present in the data. Centres reporting fewer than $60 \%$ of HD patients or fewer than $40 \%$ of PD patients being treated with ESAs were considered to have incomplete data and were excluded from further analysis. It is recognised that these exclusion criteria are relatively arbitrary but they are in part based upon the frequency distribution graph of centres' ESA use as it appears in the data. The percentage of patients on ESAs was calculated from these data and incomplete data returns risk seriously impacting on any conclusions drawn.

For analyses of ESA dose, values are presented as weekly erythropoietin dose. Doses of less than $150 \mathrm{IU} /$ week (likely to be darbepoietin) were harmonised with erythropoietin data by multiplying by 200 . No adjustments were made with respect to route of administration. Patients who were not receiving ESAs were not included in analyses of dose (rather than being included with dose $=0)$. Many centres provided data on ESA dose but not on ESA frequency. The ESA dose field is defined as the weekly dose and the dose is presumed to have been converted accordingly on submission to the UKRR. This may be an incorrect assumption for a number of patients and this needs to be considered when interpreting the ESA information.

Starting with the cohort of patients receiving ESAs in the final quarter of the year and having a dose value present for that quarter, any further dose values available from the earlier three quarters of the year were used (provided the patient was on the same treatment and receiving the same drug in those quarters). The average (mean) of the available values was then used in analyses rather than the dose in the final quarter.

The ESA data were collected electronically from renal IT systems but in contrast to laboratory linked variables the ESA data required manual data entry. The reliability depended upon the data source, whether the entry was linked to the prescription or whether the prescriptions were provided by the primary care physician. In the latter case, doses may not be as reliably updated as the link between data entry and prescription is indirect.

\section{Results}

\section{Anaemia management in incident dialysis patients}

Haemoglobin in incident dialysis patients

As the UKRR does not collect comprehensive data on patients who are not yet receiving RRT $\mathrm{Hb}$ at the time of starting RRT is the only indication of concordance with anaemia clinical practice guidelines in the pre-dialysis (CKD not (yet) on dialysis) group. The percentage data returned and outcome $\mathrm{Hb}$ are listed in table 7.2. Cambridge was unable to submit any data prior to closing the database. About 33\% of Sheffield's incident patients' data were entirely missing from the data extracts, including all their late presenters, so the cohort included is possibly not representative of all their incident dialysis patients. Stevenage did not submit any $\mathrm{Hb}$ data except for the first quarter of the year. The cause of this extraction problem has now been resolved and Stevenage are submitting $\mathrm{Hb}$ data for 2016.

The median $\mathrm{Hb}$ of patients at the time of starting dialysis in the UK in 2015 was $98 \mathrm{~g} / \mathrm{L}$. The median $\mathrm{Hb}$ for patients at the time of starting dialysis by renal centre is shown in figure 7.1. The percentage of patients starting dialysis with $\mathrm{Hb} \geqslant 100 \mathrm{~g} / \mathrm{L}$ is shown in figure 7.2. Using data from centres with adequate completeness for date of first presentation the difference in median $\mathrm{Hb}$ between early $(100 \mathrm{~g} / \mathrm{L})$ and late $(92 \mathrm{~g} / \mathrm{L})$ presenters is shown in 
Table 7.2. Haemoglobin data for incident patients starting RRT on haemodialysis or peritoneal dialysis during 2015 , both overall and by presentation time

\begin{tabular}{|c|c|c|c|c|c|c|c|}
\hline \multirow[b]{2}{*}{ Centre } & \multicolumn{3}{|c|}{ All incident dialysis patients } & \multicolumn{2}{|c|}{ Early presenters $(\geqslant 90$ days $)$} & \multicolumn{2}{|c|}{ Late presenters ( $<90$ days) } \\
\hline & $\begin{array}{l}\% \text { data } \\
\text { return }\end{array}$ & $\begin{array}{l}\text { Median } \\
\mathrm{Hb} \text { g/L }\end{array}$ & $\begin{array}{c}\% \mathrm{Hb} \\
\geqslant 100 \mathrm{~g} / \mathrm{L}\end{array}$ & $\begin{array}{l}\text { Median } \\
\mathrm{Hb} \text { g/L }\end{array}$ & $\begin{array}{c}\% \mathrm{Hb} \\
\geqslant 100 \mathrm{~g} / \mathrm{L}\end{array}$ & $\begin{array}{l}\text { Median } \\
\text { Hb g/L }\end{array}$ & $\begin{array}{c}\% \mathrm{Hb} \\
\geqslant 100 \mathrm{~g} / \mathrm{L}\end{array}$ \\
\hline \multicolumn{8}{|l|}{ England } \\
\hline B Heart & 100 & 94 & 34 & 94 & 34 & & \\
\hline $\mathrm{B}$ QEH & 100 & 99 & 48 & 99 & 49 & 95 & 43 \\
\hline Brightn & 100 & 101 & 51 & 101 & 51 & 101 & 53 \\
\hline Bristol & 100 & 105 & 78 & 104 & 79 & 104 & 73 \\
\hline Camb & $\mathrm{n} / \mathrm{a}$ & & & & & & \\
\hline Carlis & 100 & 109 & 72 & 110 & 77 & & \\
\hline Carsh & 100 & 97 & 40 & & & & \\
\hline Chelms & 100 & 106 & 66 & 107 & 67 & & \\
\hline Dorset & 97 & 103 & 54 & 105 & 67 & 87 & 8 \\
\hline Dudley & 95 & 103 & 56 & 104 & 59 & & \\
\hline Exeter & 100 & 106 & 80 & 106 & 80 & 104 & 73 \\
\hline Glouc & 98 & 103 & 58 & 103 & 58 & & \\
\hline Hull & 77 & 100 & 51 & 102 & 55 & 94 & 39 \\
\hline Ipswi & 93 & 99 & 50 & & & & \\
\hline Kent & 99 & 95 & 37 & 95 & 38 & 87 & 27 \\
\hline L Barts & 100 & 98 & 44 & & & & \\
\hline L Guys & 100 & 92 & 25 & 94 & 30 & 85 & 0 \\
\hline L Kings & 97 & 96 & 38 & 97 & 41 & 91 & 26 \\
\hline L Rfree & 98 & 100 & 50 & 100 & 52 & 96 & 41 \\
\hline L St.G & 86 & 92 & 29 & & & & \\
\hline Norwch & 99 & 96 & 37 & & & & \\
\hline Nottm & 99 & 92 & 32 & 92 & 33 & 81 & 8 \\
\hline Oxford & 100 & 97 & 44 & 99 & 48 & 87 & 20 \\
\hline Plymth & 100 & 100 & 52 & 108 & 65 & & \\
\hline Ports & 99 & 100 & 52 & & & & \\
\hline Prestn & 100 & 99 & 46 & 99 & 49 & 97 & 35 \\
\hline Redng & 99 & 100 & 53 & 102 & 63 & 83 & 8 \\
\hline Salford & 100 & 96 & 38 & & & & \\
\hline Sheff* & 100 & 100 & 51 & 100 & 51 & & \\
\hline Shrew & 98 & 102 & 57 & & & & \\
\hline Stevng & 26 & & & & & & \\
\hline Sthend & 100 & 96 & 43 & 97 & 45 & & \\
\hline Stoke & 97 & 101 & 56 & 102 & 59 & 94 & 38 \\
\hline Sund & 97 & 99 & 48 & 99 & 47 & & \\
\hline Truro & 100 & 103 & 59 & 103 & 64 & 96 & 47 \\
\hline Wirral & 96 & 99 & 48 & & & & \\
\hline Wolve & 96 & 93 & 40 & 97 & 44 & 80 & 21 \\
\hline York & 92 & 97 & 43 & 98 & 47 & 95 & 30 \\
\hline
\end{tabular}


Table 7.2. Continued

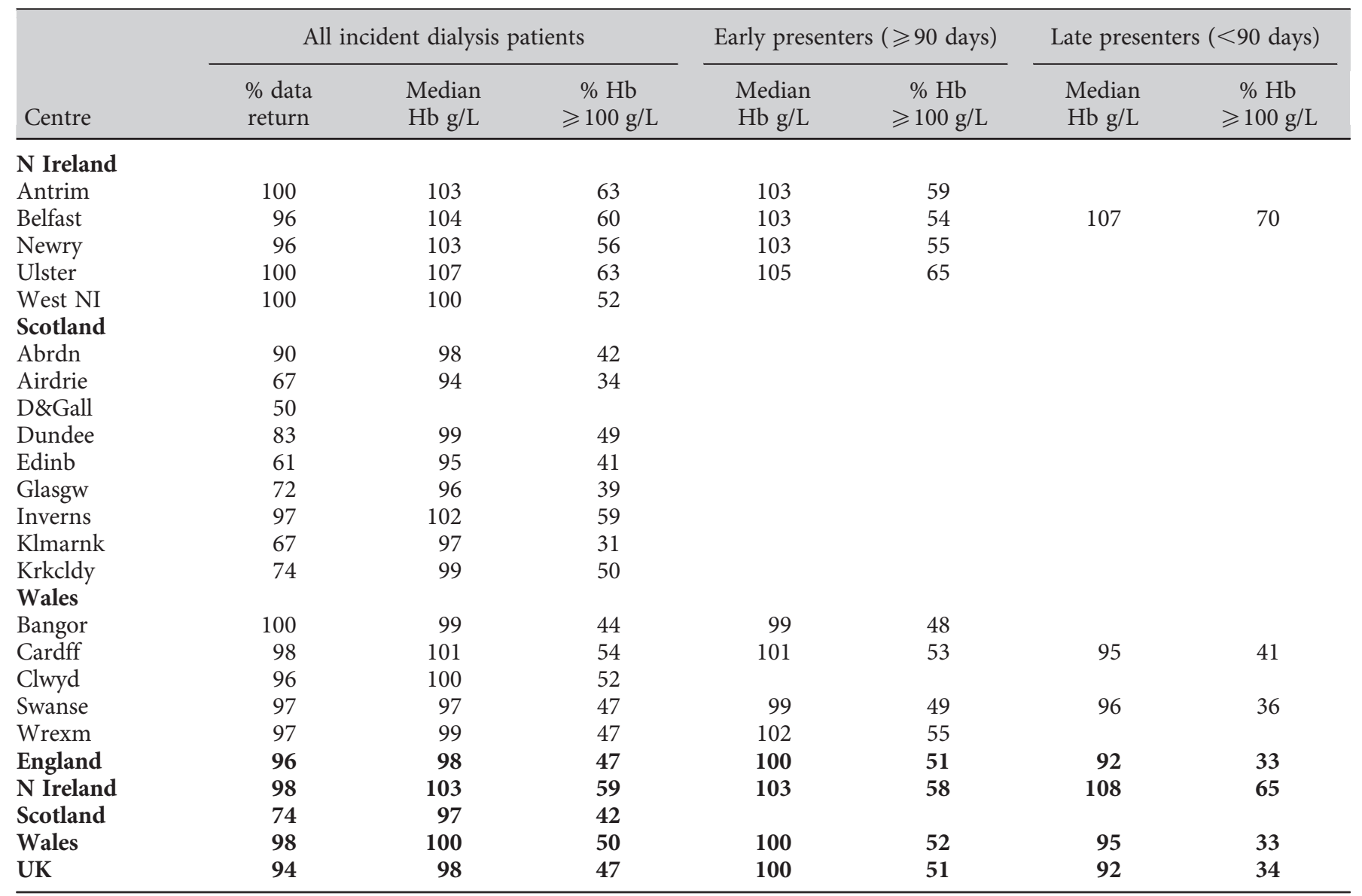

n/a: not available

Blank cells: centres excluded from the analysis due to poor data completeness or low patient numbers

*Sheffield: approximately $33 \%$ of their incident patients were missing from the analysis, including all late presenters so the group analysed may not be representative of their whole cohort

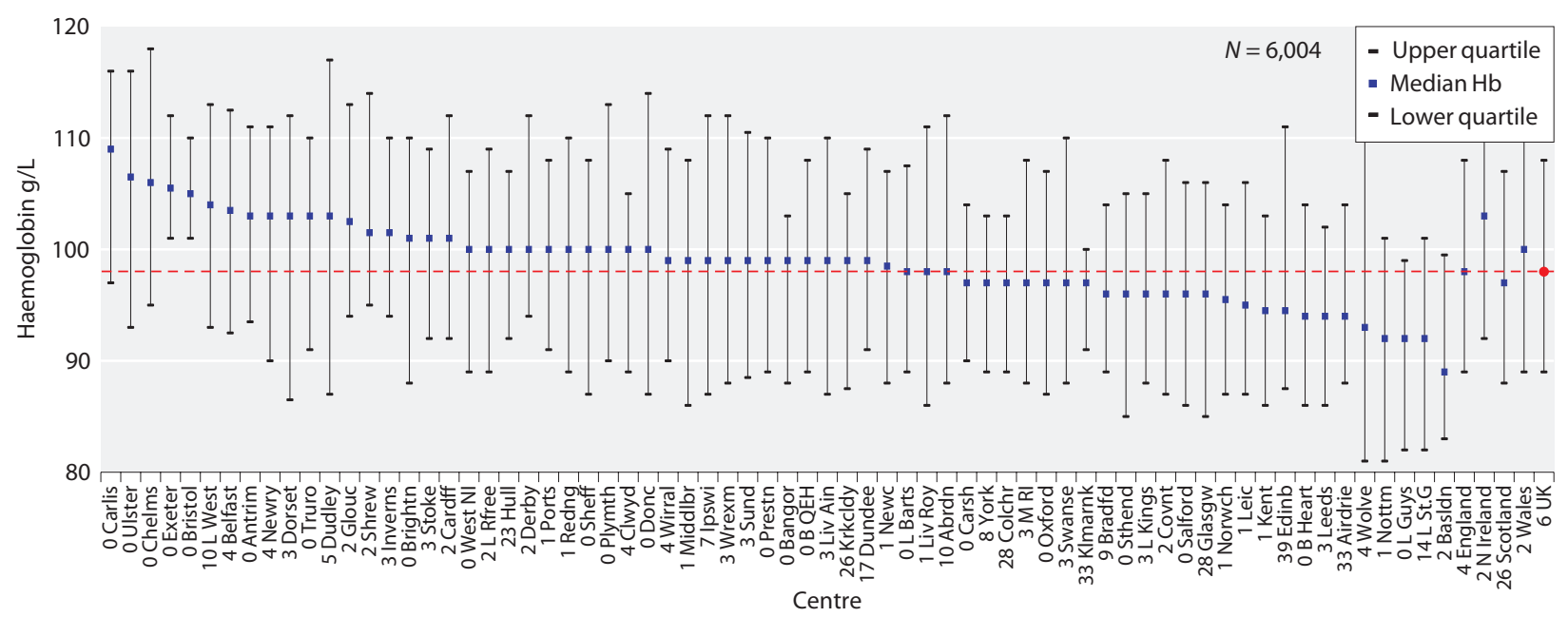

Fig. 7.1. Median haemoglobin for incident dialysis patients at start of dialysis treatment in 2015 


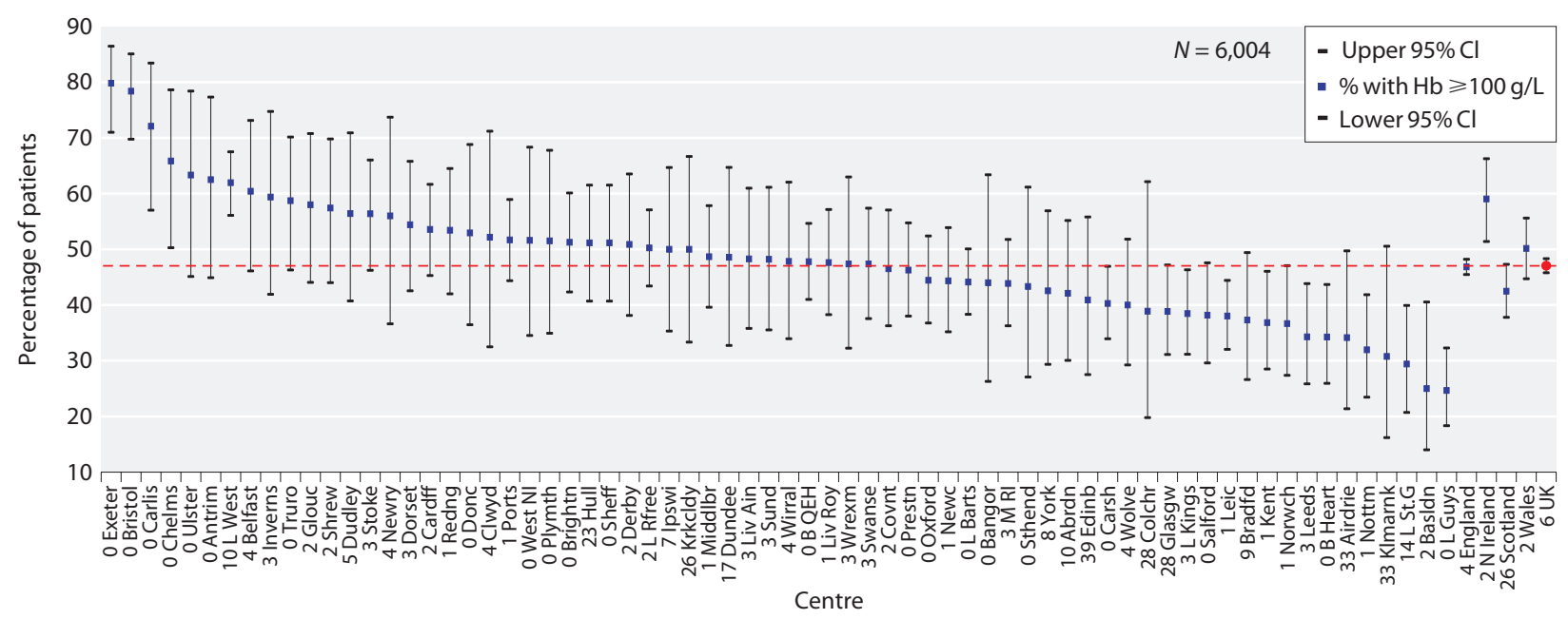

Fig. 7.2. Percentage of incident dialysis patients with $\mathrm{Hb} \geqslant 100 \mathrm{~g} / \mathrm{L}$ at start of dialysis treatment in 2015

table 7.2. Of early presenters, $51 \%$ had a $\mathrm{Hb} \geqslant 100 \mathrm{~g} / \mathrm{L}$ compared with $34 \%$ of late presenters.

Again, there is a substantial difference between $\mathrm{Hb}$ at the time of starting dialysis by modality. Patients starting on $\mathrm{HD}$ had a median $\mathrm{Hb}$ of $96 \mathrm{~g} / \mathrm{L}$ (IQR 87-105) whilst those starting on $\mathrm{PD}$ had a median $\mathrm{Hb}$ of $107 \mathrm{~g} / \mathrm{L}$ (IQR 98-116). Of HD patients, 40\% started dialysis with a $\mathrm{Hb} \geqslant 100 \mathrm{~g} / \mathrm{L}$ compared with $73 \%$ of PD patients.

Incident dialysis patients from 2014 were followed for one year and the median haemoglobin and percentage with $\geqslant 100 \mathrm{~g} / \mathrm{L}$ in survivors on the same treatment at the same centre were calculated for each quarter. Only patients with $\mathrm{Hb}$ data for each of the four time points were included in this analysis. Results by modality and length of pre-dialysis care are shown in figures 7.3 and

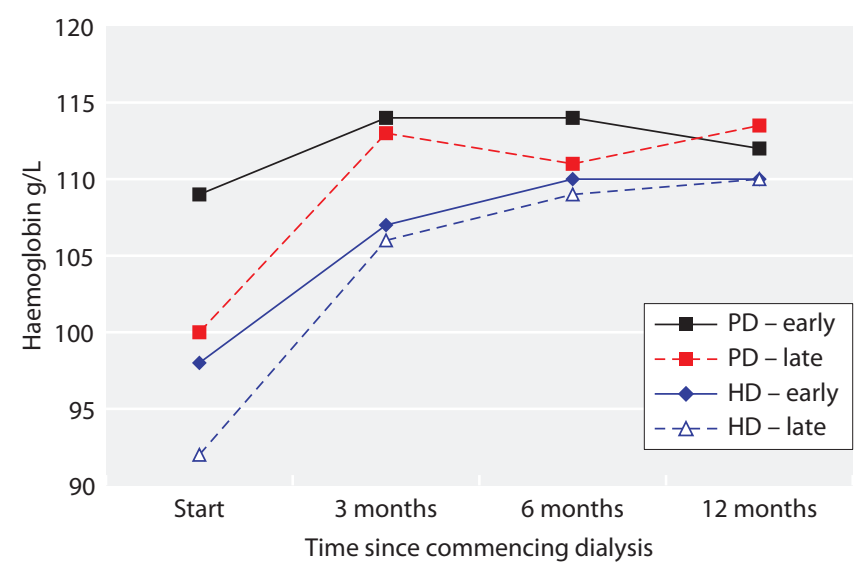

Fig. 7.3. Median haemoglobin, by time on dialysis and length of pre-RRT care, for incident dialysis patients in 2014
7.4. The 'PD-late' group consisted of only 30 patients so care should be taken in interpreting the results.

The distribution of $\mathrm{Hb}$ ranges in incident dialysis patients by year of start is shown in figure 7.5. The proportion of incident dialysis patients with $\mathrm{Hb}$ $\geqslant 120 \mathrm{~g} / \mathrm{L}$ has fallen from $17.2 \%$ in 2006 to $8.4 \%$ in 2015. In contrast, the proportion of patients starting dialysis with $\mathrm{Hb}<100 \mathrm{~g} / \mathrm{L}$ has increased from $40.0 \%$ in 2006 to $53.2 \%$ in 2015 .

The proportion of patients receiving an ESA by length of time on dialysis for patients starting dialysis in 2014 is shown in figure 7.6. The difference in ESA use between early and late starters was reduced substantially after six months of treatment. Only 11 patients presenting late to dialysis and starting on PD had ESA data so this group has not been included in the analysis.

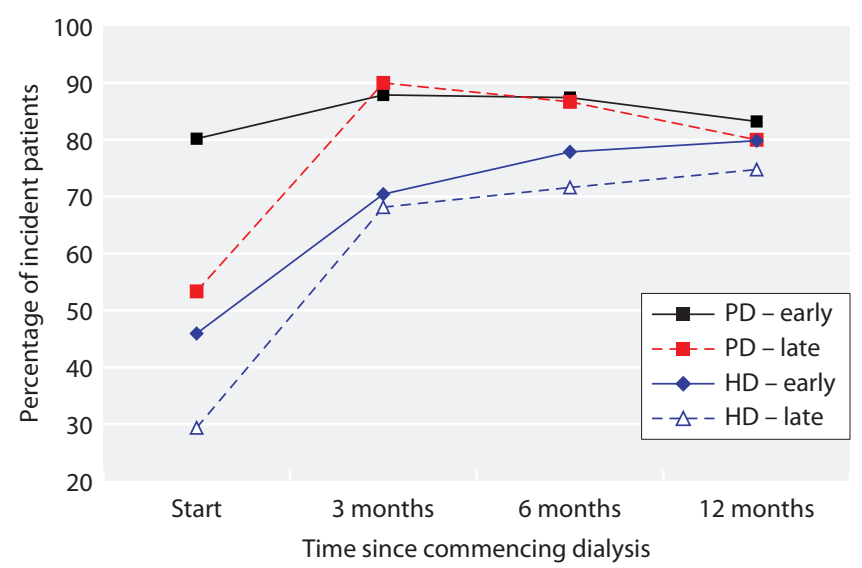

Fig. 7.4. Percentage of incident dialysis patients in 2014 with $\mathrm{Hb}$ $\geqslant 100 \mathrm{~g} / \mathrm{L}$ by time on dialysis and by length of pre-RRT care 


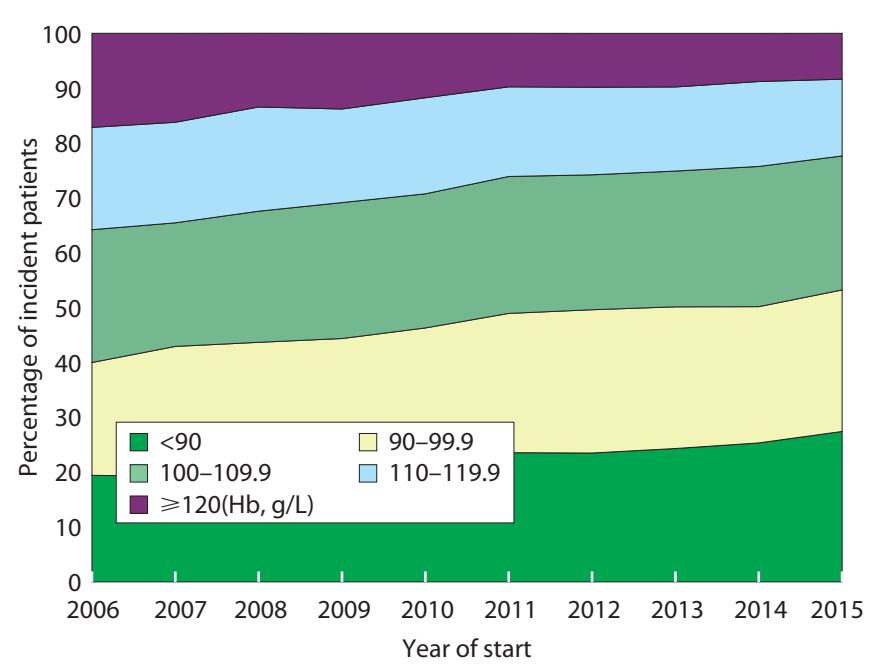

Fig. 7.5. Distribution of haemoglobin in incident dialysis patients by year of start

Anaemia management in prevalent dialysis patients

Compliance with data returns for $\mathrm{Hb}$ and serum ferritin are shown in table 7.3. Data completeness was generally good for $\mathrm{Hb}$ and ferritin. Cambridge did not

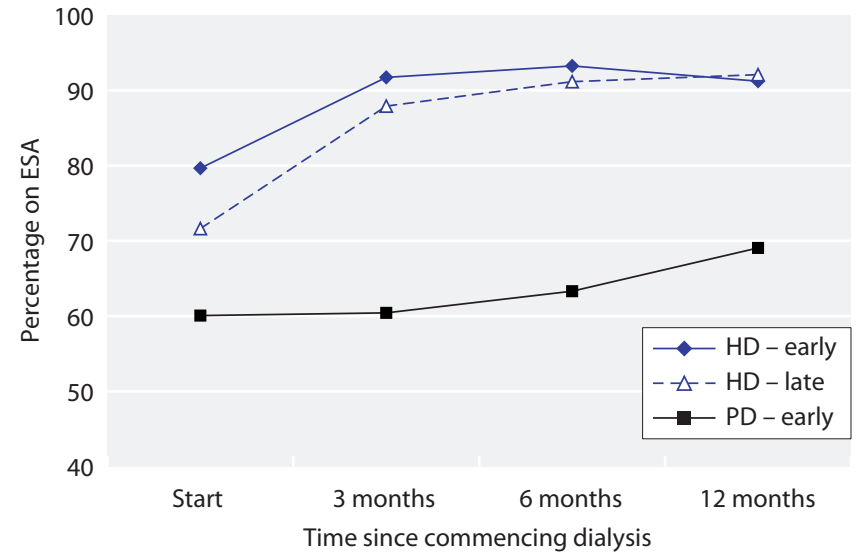

Fig. 7.6. Percentage of incident dialysis patients in 2014 on ESA, by time on dialysis and by length of pre-RRT care

submit any data prior to closing the database. Stevenage did not submit any $\mathrm{Hb}$ data except for the first quarter of the year. This Q1 data has been shown in tables 7.4 and 7.5 but not used in the figures. Salford did not submit any ferritin data. Percentages of patients reportedly receiving ESAs are shown in table 7.3. These are as

Table 7.3. Percentage completeness of data returns for haemoglobin and serum ferritin and percentages on ESA for prevalent HD and PD patients in 2015

\begin{tabular}{|c|c|c|c|c|c|c|c|c|}
\hline \multirow[b]{2}{*}{ Centre } & \multicolumn{4}{|c|}{ HD } & \multicolumn{4}{|c|}{$\mathrm{PD}$} \\
\hline & $N$ & $\mathrm{Hb}$ & Ferritin & $\%$ on ESA & $N$ & $\mathrm{Hb}$ & Ferritin & $\%$ on ESA \\
\hline B Heart & 397 & 100 & 99 & 78 & 40 & 100 & 90 & 55 \\
\hline B QEH & 933 & 100 & 99 & 88 & 121 & 100 & 100 & 64 \\
\hline Basldn & 153 & 99 & 99 & 92 & 27 & 100 & 100 & 89 \\
\hline Bristol & 489 & 100 & 100 & 93 & 47 & 100 & 96 & 74 \\
\hline \multicolumn{9}{|l|}{ Camb } \\
\hline Carlis & 74 & 100 & 100 & 69 & 30 & 100 & 97 & 63 \\
\hline Carsh & 761 & 100 & 99 & 13 & 101 & 95 & 92 & 0 \\
\hline Chelms & 139 & 99 & 99 & 92 & 23 & 96 & 87 & 65 \\
\hline Colchr & 111 & 95 & 94 & 5 & & & & \\
\hline Dudley & 155 & 100 & 100 & 3 & 52 & 100 & 94 & 2 \\
\hline Exeter & 403 & 100 & 100 & 94 & 71 & 99 & 100 & 76 \\
\hline Glouc & 216 & 100 & 96 & 90 & 28 & 100 & 93 & 61 \\
\hline Hull & 327 & 100 & 100 & 62 & 66 & 98 & 98 & 47 \\
\hline Ipswi & 129 & 100 & 100 & 67 & 27 & 100 & 100 & 0 \\
\hline Kent & 397 & 100 & 100 & 94 & 54 & 100 & 98 & 46 \\
\hline L Barts & 928 & 100 & 100 & 0 & 182 & 99 & 96 & 0 \\
\hline L Guys & 629 & 100 & 100 & 0 & 29 & 100 & 93 & 0 \\
\hline L Kings & 522 & 100 & 98 & 92 & 80 & 100 & 100 & 78 \\
\hline L Rfree & 665 & 100 & 100 & 0 & 134 & 100 & 99 & 0 \\
\hline L St.G & 311 & 97 & 96 & 0 & 45 & 98 & 100 & 0 \\
\hline
\end{tabular}


Table 7.3. Continued

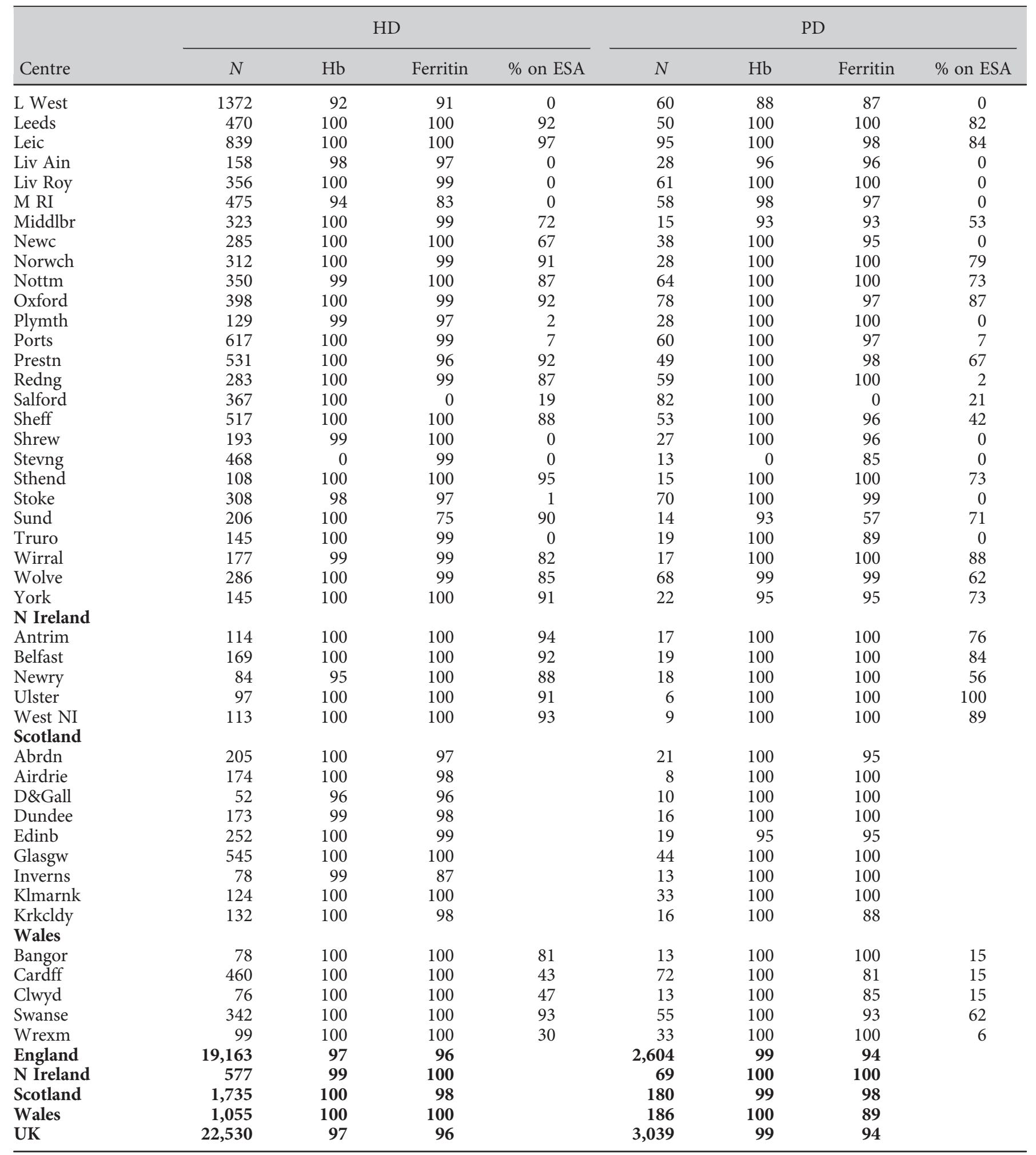

Blank cells denote centres with no PD patients or because data were not available

Percentages of patients receiving ESA are shown but centres with less than $60 \%$ HD patients or $40 \%$ PD patients on ESA have been excluded (see text). Therefore, country averages are not shown - these can be found in tables 7.4 and 7.5 
Table 7.4. Summary statistics for haemoglobin, serum ferritin and ESA for prevalent HD patients in 2015

\begin{tabular}{|c|c|c|c|c|c|c|c|c|c|c|}
\hline Centre & $\begin{array}{l}N \text { with } \\
\mathrm{Hb} \text { data }\end{array}$ & $\begin{array}{l}\text { Median } \\
\mathrm{Hb} \text { g/L }\end{array}$ & $\begin{array}{c}\% \mathrm{Hb} \\
\geqslant 100 \mathrm{~g} / \mathrm{L}\end{array}$ & $\begin{array}{c}\% \mathrm{Hb} \\
100- \\
120 \mathrm{~g} / \mathrm{L}\end{array}$ & $\begin{array}{l}\text { Median } \\
\text { ferritin } \\
\mu \mathrm{g} / \mathrm{L}\end{array}$ & $\begin{array}{l}\% \text { ferritin } \\
\geqslant 100 \mu \mathrm{g} / \mathrm{L}\end{array}$ & $\begin{array}{l}\% \text { ferritin } \\
>200 \text { and } \\
\leqslant 500 \mu \mathrm{g} / \mathrm{L}\end{array}$ & $\begin{array}{c}\% \text { on } \\
\text { ESA }\end{array}$ & $\begin{array}{l}\text { Median } \\
\text { ESA dose } \\
\text { (IU/week) }\end{array}$ & $\begin{array}{c}\% \text { with } \\
\geqslant 100 \mathrm{~g} / \mathrm{I} \\
\text { not on }\end{array}$ \\
\hline \multicolumn{11}{|l|}{ England } \\
\hline B Heart & 396 & 109 & 76 & 57 & 295 & 92 & 58 & 78 & 6,667 & 20 \\
\hline B QEH & 929 & 109 & 75 & 61 & 392 & 95 & 61 & 88 & 6,000 & 10 \\
\hline Basldn & 152 & 110 & 77 & 60 & 294 & 91 & 72 & 92 & 7,000 & 7 \\
\hline Bradfd & 217 & 109 & 77 & 54 & 474 & 95 & 42 & 94 & 7,000 & 4 \\
\hline Brightn & 402 & 110 & 79 & 54 & 478 & 98 & 46 & 83 & 5,350 & 15 \\
\hline Bristol & 489 & 112 & 92 & 69 & 540 & 95 & 35 & 93 & 8,000 & 7 \\
\hline \multicolumn{11}{|l|}{ Camb } \\
\hline Carlis & 74 & 114 & 85 & 53 & 745 & 95 & 16 & 69 & 5,333 & 30 \\
\hline Carsh & 760 & 109 & 79 & 65 & 330 & 93 & 65 & & & \\
\hline Chelms & 138 & 113 & 87 & 60 & 614 & 97 & 22 & 92 & 10,625 & 7 \\
\hline Colchr & 105 & 112 & 90 & 68 & 532 & 96 & 38 & & & \\
\hline Covnt & 332 & 106 & 69 & 59 & 396 & 96 & 61 & 84 & 9,000 & 13 \\
\hline Derby & 221 & 115 & 86 & 59 & 485 & 96 & 38 & & & \\
\hline Donc & 163 & 108 & 70 & 56 & 403 & 94 & 50 & 89 & 6,000 & 11 \\
\hline Dorset & 270 & 112 & 86 & 64 & 452 & 99 & 55 & 93 & 7,000 & 7 \\
\hline Dudley & 155 & 115 & 85 & 55 & 325 & 94 & 61 & & & \\
\hline Exeter & 403 & 112 & 95 & 73 & 296 & 92 & 60 & 94 & 6,500 & 6 \\
\hline Glouc & 216 & 109 & 79 & 65 & 421 & 91 & 45 & 90 & & 10 \\
\hline Hull & 326 & 113 & 81 & 55 & 389 & 96 & 58 & 62 & 5,000 & 30 \\
\hline Ipswi & 129 & 112 & 82 & 67 & 539 & 96 & 36 & 67 & 7,385 & 29 \\
\hline Kent & 395 & 109 & 76 & 56 & 418 & 90 & 37 & 94 & 8,875 & 6 \\
\hline L Barts & 928 & 111 & 82 & 64 & 635 & 96 & 23 & & & \\
\hline L Guys & 629 & 109 & 75 & 61 & 481 & 93 & 35 & & & \\
\hline L Kings & 522 & 107 & 76 & 64 & 452 & 94 & 38 & 92 & 8,000 & 8 \\
\hline L Rfree & 665 & 109 & 77 & 61 & 527 & 95 & 36 & & & \\
\hline L St.G & 302 & 107 & 73 & 60 & 429 & 94 & 50 & & & \\
\hline L West & 1,266 & 113 & 86 & 65 & 321 & 94 & 59 & & & \\
\hline Leeds & 470 & 108 & 74 & 61 & 482 & 95 & 42 & 92 & 5,250 & 7 \\
\hline Leic & 839 & 111 & 77 & 51 & 338 & 94 & 62 & 97 & 6,000 & 2 \\
\hline Liv Ain & 155 & 108 & 70 & 54 & 407 & 86 & 34 & & & \\
\hline Liv Roy & 355 & 112 & 81 & 55 & 332 & 88 & 43 & & & \\
\hline M RI & 448 & 111 & 76 & 54 & 347 & 94 & 56 & & & \\
\hline Middlbr & 323 & 111 & 78 & 57 & 939 & 97 & 18 & 72 & 5,250 & 24 \\
\hline Newc & 285 & 111 & 79 & 55 & 347 & 90 & 43 & 67 & 13,267 & 29 \\
\hline Norwch & 312 & 115 & 80 & 49 & 484 & 91 & 34 & 91 & 9,500 & 9 \\
\hline Nottm & 346 & 110 & 80 & 61 & 496 & 97 & 44 & 87 & 7,500 & 13 \\
\hline Oxford & 396 & 108 & 72 & 56 & 291 & 89 & 51 & 92 & 12,000 & 8 \\
\hline Plymth & 128 & 111 & 78 & 57 & 741 & 93 & 21 & & & \\
\hline Ports & 616 & 113 & 81 & 54 & 394 & 93 & 51 & & & \\
\hline Prestn & 531 & 109 & 76 & 56 & 594 & 95 & 29 & 92 & & 8 \\
\hline Redng & 283 & 114 & 78 & 49 & 477 & 98 & 43 & 87 & 13,154 & 7 \\
\hline Salford & 366 & 110 & 77 & 57 & & & & & & \\
\hline Sheff & 515 & 111 & 76 & 51 & 468 & 95 & 46 & 88 & 7,500 & 10 \\
\hline Shrew & 192 & 116 & 86 & 52 & 348 & 94 & 61 & & & \\
\hline Stevng ${ }^{a}$ & & $108^{\mathrm{a}}$ & $76^{\mathrm{a}}$ & $61^{\mathrm{a}}$ & 667 & 98 & 23 & & & \\
\hline Sthend & 108 & 108 & 80 & 71 & 315 & 95 & 81 & 95 & 9,250 & 4 \\
\hline Stoke & 301 & 111 & 80 & 58 & 267 & 90 & 45 & & & \\
\hline Sund & 205 & 112 & 77 & 51 & 344 & 94 & 40 & 90 & 9,615 & 9 \\
\hline Truro & 145 & 106 & 76 & 66 & 408 & 99 & 59 & & & \\
\hline Wirral & 176 & 109 & 83 & 68 & 432 & 95 & 52 & 82 & 9,000 & 16 \\
\hline Wolve & 285 & 114 & 84 & 50 & 459 & 92 & 43 & 85 & 8,000 & 14 \\
\hline York & 145 & 110 & 81 & 68 & 400 & 96 & 70 & 91 & 4,833 & 9 \\
\hline \multicolumn{11}{|l|}{ N Ireland } \\
\hline Antrim & 114 & 108 & 75 & 64 & 392 & 92 & 51 & 94 & 7,000 & 6 \\
\hline Belfast & 169 & 110 & 80 & 56 & 465 & 92 & 37 & 92 & 8,000 & 6 \\
\hline Newry & 80 & 109 & 76 & 60 & 384 & 93 & 49 & 88 & 5,750 & 13 \\
\hline Ulster & 97 & 114 & 87 & 57 & 672 & 98 & 14 & 91 & 5,000 & 9 \\
\hline West NI & 113 & 111 & 85 & 62 & 535 & 95 & 32 & 93 & 6,667 & 7 \\
\hline
\end{tabular}


Table 7.4. Continued

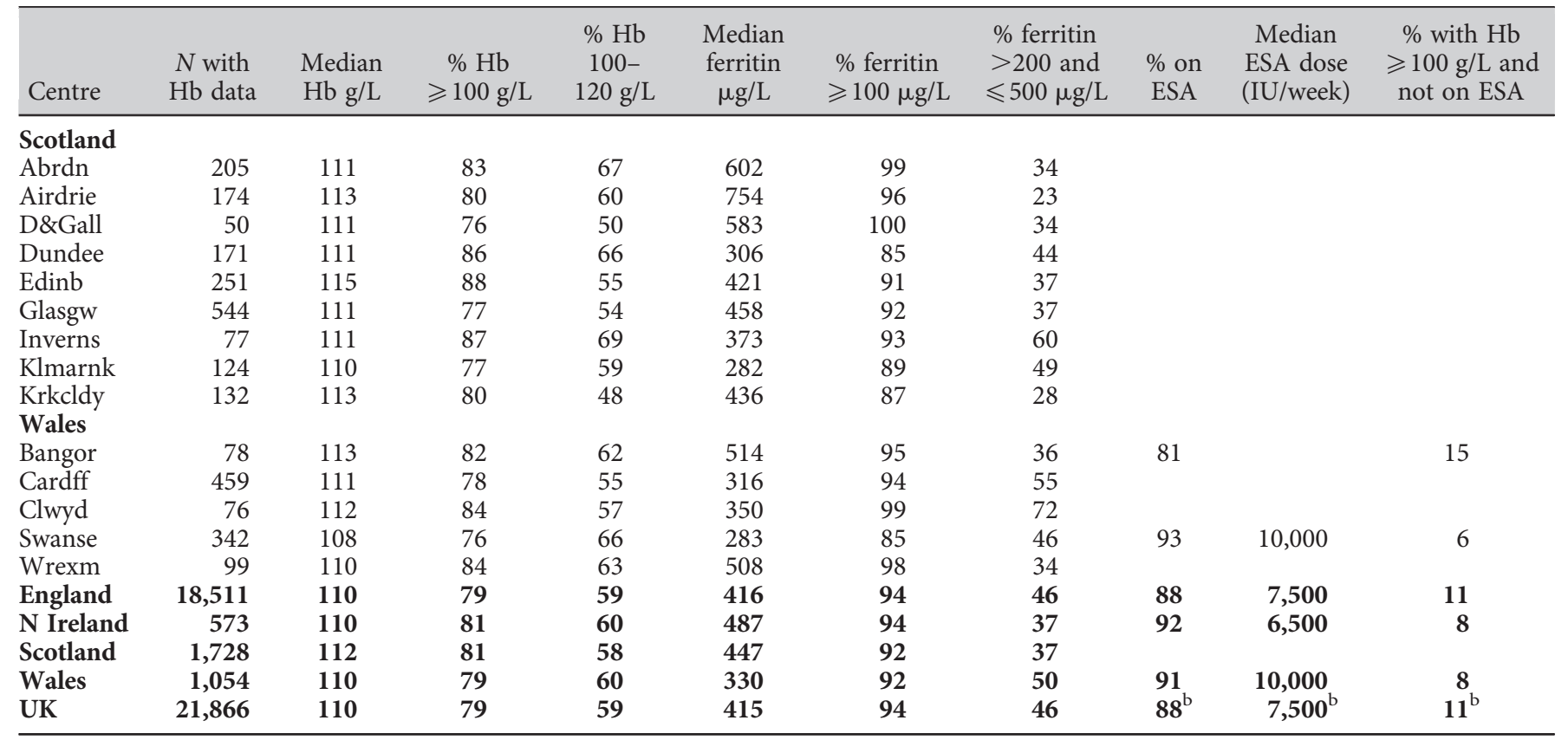

Blank cells denote centres excluded from analyses due to poor data completeness or low patient numbers or because the data item was not available

${ }^{\mathrm{a}}$ Data from Q1 only

${ }^{b}$ ESA summary results are for E, W \& NI (not UK)

ESA data only shown for those centres where the percentage on ESA was $60 \%$ or more

Table 7.5. Summary statistics for haemoglobin, serum ferritin and ESA for prevalent PD patients in 2015

\begin{tabular}{|c|c|c|c|c|c|c|c|c|c|c|}
\hline Centre & $\begin{array}{l}N \text { with } \\
\mathrm{Hb} \text { data }\end{array}$ & $\begin{array}{l}\text { Median } \\
\mathrm{Hb} \text { g/L }\end{array}$ & $\begin{array}{c}\% \mathrm{Hb} \\
\geqslant 100 \mathrm{~g} / \mathrm{L}\end{array}$ & $\begin{array}{c}\% \mathrm{Hb} \\
100- \\
120 \mathrm{~g} / \mathrm{L}\end{array}$ & $\begin{array}{c}\text { Median } \\
\text { ferritin } \\
\mu \mathrm{g} / \mathrm{L}\end{array}$ & $\begin{array}{l}\% \text { ferritin } \\
\geqslant 100 \mu \mathrm{g} / \mathrm{L}\end{array}$ & $\begin{array}{l}\% \text { ferritin } \\
>100 \text { and } \\
\leqslant 500 \mu \mathrm{g} / \mathrm{L}\end{array}$ & $\begin{array}{c}\% \text { on } \\
\text { ESA }\end{array}$ & $\begin{array}{l}\text { Median } \\
\text { ESA dose } \\
\text { (IU/week) }\end{array}$ & $\begin{array}{l}\% \text { with } \mathrm{Hb} \\
\geqslant 100 \mathrm{~g} / \mathrm{L} \text { and } \\
\text { not on ESA }\end{array}$ \\
\hline \multicolumn{11}{|l|}{ England } \\
\hline $\mathrm{B} \mathrm{QEH}$ & 121 & 111 & 76 & 55 & 327 & 91 & 72 & 64 & 4,000 & 35 \\
\hline Basldn & 27 & 104 & 78 & 78 & 185 & 81 & 70 & 89 & 4,250 & 11 \\
\hline Bradfd & 14 & 109 & 79 & 64 & 237 & 85 & 46 & 86 & 8,000 & 14 \\
\hline Carlis & 30 & 113 & 87 & 63 & 291 & 83 & 62 & 63 & 3,333 & 37 \\
\hline Carsh & 96 & 108 & 79 & 59 & 186 & 81 & 73 & & & \\
\hline Chelms & 22 & 116 & 91 & 55 & 156 & 55 & 50 & 65 & 2,500 & 36 \\
\hline Colchr & $\mathrm{n} / \mathrm{a}$ & & & & & & & & & \\
\hline Covnt & 75 & 109 & 72 & 55 & 238 & 86 & 66 & 61 & 8,000 & 32 \\
\hline Derby & 73 & 112 & 79 & 55 & 408 & 97 & 58 & & & \\
\hline Glouc & 28 & 111 & 86 & 54 & 147 & 62 & 46 & 61 & & 29 \\
\hline Hull & 65 & 111 & 88 & 75 & 332 & 97 & 77 & 47 & 4,000 & 49 \\
\hline Ipswi & 27 & 109 & 67 & 37 & 346 & 85 & 48 & & & \\
\hline Kent & 54 & 109 & 81 & 67 & 274 & 94 & 77 & 46 & 4,000 & 43 \\
\hline L Barts & 180 & 110 & 80 & 56 & 280 & 87 & 59 & & & \\
\hline L Guys & 29 & 102 & 52 & 41 & 207 & 89 & 78 & & & \\
\hline L Kings & 80 & 109 & 76 & 56 & 215 & 90 & 81 & 78 & 4,000 & 21 \\
\hline L Rfree & 134 & 109 & 79 & 56 & 613 & 94 & 34 & & & \\
\hline
\end{tabular}


Table 7.5. Continued

\begin{tabular}{|c|c|c|c|c|c|c|c|c|c|c|}
\hline Centre & $\begin{array}{l}N \text { with } \\
\mathrm{Hb} \text { data }\end{array}$ & $\begin{array}{l}\text { Median } \\
\mathrm{Hb} \text { g/L }\end{array}$ & $\begin{array}{c}\% \mathrm{Hb} \\
\geqslant 100 \mathrm{~g} / \mathrm{L}\end{array}$ & $\begin{array}{c}\% \mathrm{Hb} \\
100- \\
120 \mathrm{~g} / \mathrm{L}\end{array}$ & $\begin{array}{l}\text { Median } \\
\text { ferritin } \\
\mu \mathrm{g} / \mathrm{L}\end{array}$ & $\begin{array}{l}\% \text { ferritin } \\
\geqslant 100 \mu \mathrm{g} / \mathrm{L}\end{array}$ & $\begin{array}{l}\% \text { ferritin } \\
>100 \text { and } \\
\leqslant 500 \mu \mathrm{g} / \mathrm{L}\end{array}$ & $\begin{array}{l}\% \text { on } \\
\text { ESA }\end{array}$ & $\begin{array}{l}\text { Median } \\
\text { ESA dose } \\
\text { (IU/week) }\end{array}$ & $\begin{array}{c}\% \text { with } \mathrm{Hb} \\
\geqslant 100 \mathrm{~g} / \mathrm{L} \text { and } \\
\text { not on ESA }\end{array}$ \\
\hline L St.G & 44 & 109 & 66 & 50 & 335 & 93 & 69 & & & \\
\hline Leeds & 50 & 115 & 88 & 60 & 365 & 92 & 70 & 82 & 4,585 & 18 \\
\hline Leic & 95 & 111 & 84 & 64 & 301 & 94 & 72 & 84 & 3,000 & 15 \\
\hline Liv Ain & 27 & 116 & 89 & 44 & 492 & 89 & 44 & & & \\
\hline Middlbr & 14 & 118 & 100 & 71 & 388 & 93 & 64 & 53 & & 43 \\
\hline Newc & 38 & 111 & 82 & 58 & 455 & 92 & 50 & & & \\
\hline Norwch & 28 & 119 & 86 & 39 & 306 & 82 & 54 & 79 & 4,000 & 21 \\
\hline Nottm & 64 & 108 & 69 & 52 & 539 & 97 & 34 & 73 & 3,200 & 23 \\
\hline Oxford & 78 & 110 & 85 & 67 & 256 & 89 & 76 & 87 & 6,000 & 13 \\
\hline Plymth & 28 & 115 & 82 & 46 & 531 & 96 & 39 & & & \\
\hline Shrew & 27 & 108 & 70 & 52 & 182 & 85 & 69 & & & \\
\hline Stevng ${ }^{a}$ & & $111^{\mathrm{a}}$ & $82^{\mathrm{a}}$ & $59^{\mathrm{a}}$ & 260 & 91 & 73 & & & \\
\hline Sthend & 15 & 116 & 80 & 60 & 244 & 87 & 73 & 73 & & 27 \\
\hline Stoke & 70 & 114 & 80 & 50 & 266 & 93 & 77 & & & \\
\hline Sund & 13 & 110 & 85 & 54 & & & & 71 & 2,769 & 31 \\
\hline Truro & 19 & 117 & 79 & 37 & 206 & 88 & 88 & & & \\
\hline Wirral & 17 & 109 & 71 & 71 & 453 & 100 & 65 & 88 & 6,000 & 12 \\
\hline Wolve & 67 & 110 & 72 & 46 & 158 & 61 & 55 & 62 & 5,550 & 31 \\
\hline York & 21 & 109 & 67 & 52 & 362 & 90 & 71 & 73 & 3,750 & 19 \\
\hline \multicolumn{11}{|l|}{ N Ireland } \\
\hline Antrim & 17 & 109 & 76 & 76 & 325 & 94 & 71 & 76 & 3,000 & 18 \\
\hline Belfast & 19 & 114 & 95 & 74 & 361 & 95 & 63 & 84 & 3,875 & 16 \\
\hline Newry & 18 & 109 & 78 & 56 & 371 & 100 & 78 & 56 & 4,000 & 44 \\
\hline Glasgw & 44 & 117 & 84 & 50 & 191 & 80 & 64 & & & \\
\hline Inverns & 13 & 106 & 77 & 46 & 210 & 92 & 92 & & & \\
\hline Klmarnk & 33 & 115 & 82 & 55 & 219 & 91 & 73 & & & \\
\hline Krkcldy & 16 & 117 & 94 & 63 & 256 & 71 & 29 & & & \\
\hline \multicolumn{11}{|l|}{ Wales } \\
\hline Bangor & 13 & 115 & 92 & 69 & 186 & 85 & 77 & & & \\
\hline Cardff & 72 & 116 & 82 & 46 & 118 & 64 & 59 & & & \\
\hline Clwyd & 13 & 108 & 85 & 62 & 417 & 91 & 55 & & & \\
\hline Swanse & 55 & 112 & 84 & 60 & 318 & 90 & 65 & 62 & 4,125 & 36 \\
\hline Wrexm & 33 & 112 & 82 & 58 & 303 & 88 & 70 & & & \\
\hline England & 2,566 & 112 & 81 & 57 & 301 & 89 & 63 & 69 & 4,000 & 28 \\
\hline N Ireland & 69 & 111 & 84 & 62 & 361 & 96 & 65 & 77 & 4,000 & 22 \\
\hline Scotland & 179 & 115 & 84 & 51 & 237 & 86 & 66 & & & \\
\hline Wales & 186 & 113 & 83 & 55 & 217 & 80 & 64 & 62 & 4,125 & 36 \\
\hline UK & 3,000 & 112 & 81 & 57 & 295 & 88 & 64 & $69^{b}$ & $4,000^{b}$ & $28^{\mathrm{b}}$ \\
\hline
\end{tabular}

Blank cells denote centres excluded from analyses due to poor data completeness or low patient numbers or because the data item was not available

${ }^{\mathrm{a}}$ Data from Q1 only

${ }^{b}$ ESA summary results are for E, W \& NI (not UK)

ESA data only shown for those centres where the percentage on ESA was $40 \%$ or more

Anaemia Management in UK dialysis

Nephron 2017;137(suppl1):165-188 


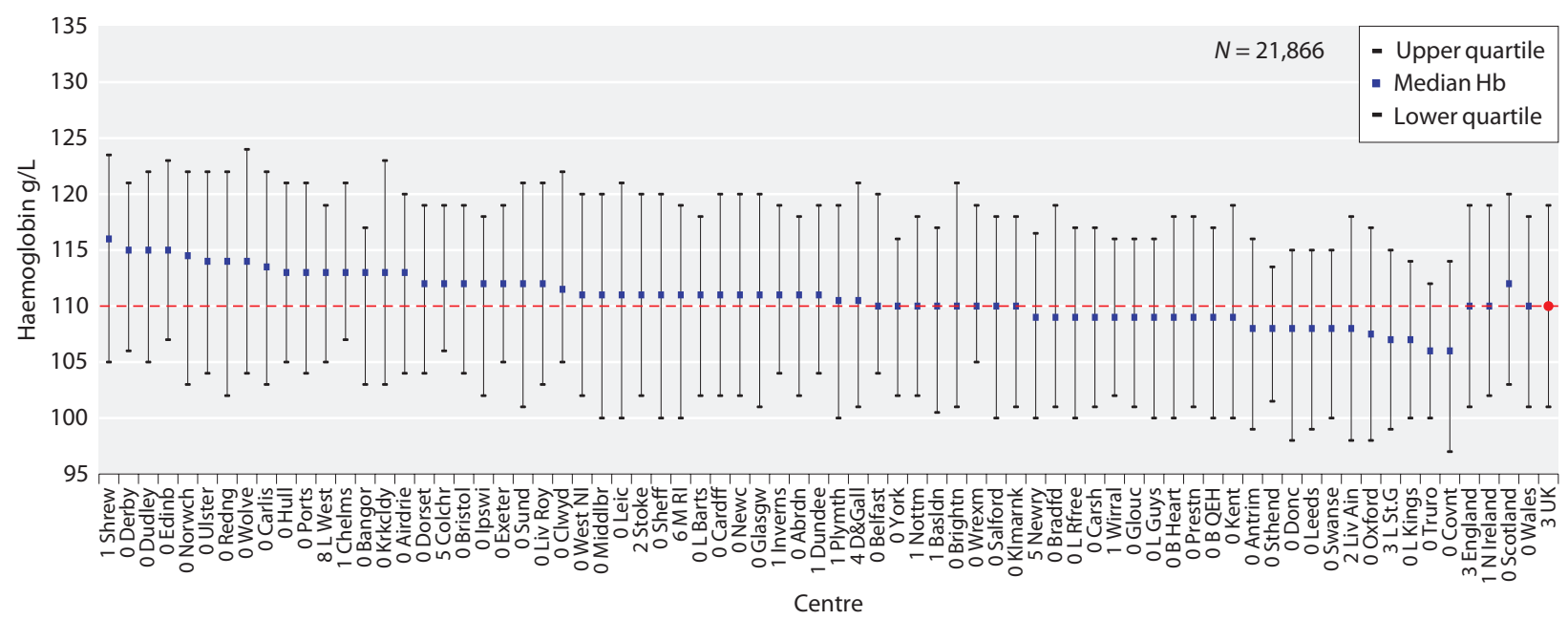

Fig. 7.7. Median haemoglobin in patients treated with HD by centre in 2015

received by the UKRR. As stated in the methods section, centres returning unexpectedly low ESA returns were assumed to have had problems with data entry and/or data transfer. Centres were excluded from further ESA analyses if they reported ESA use in less than $60 \%$ of HD patients or less than $40 \%$ of PD patients.

Summary statistics for haemoglobin, serum ferritin and ESA are shown in table 7.4 for $\mathrm{HD}$ and 7.5 for PD.

\section{Haemoglobin in prevalent haemodialysis patients}

The median $\mathrm{Hb}$ of patients on HD in the UK in 2015 was $110 \mathrm{~g} / \mathrm{L}$ (IQR 101-119) and is shown in table 7.4. For $\mathrm{HD}$ patients $79 \%$ had a $\mathrm{Hb} \geqslant 100 \mathrm{~g} / \mathrm{L}$. Figure 7.7 shows the median $\mathrm{Hb}$ in $\mathrm{HD}$ patients by renal centre. Figure 7.8 shows the proportion of patients by centre with $\mathrm{Hb}$ within the Renal Association guideline range (100$120 \mathrm{~g} / \mathrm{L}$ ) and figure 7.9 shows the distribution of $\mathrm{Hb}$ within, above and below this range.

Funnel plots for the percentage of patients with $\mathrm{Hb}$ $\geqslant 100 \mathrm{~g} / \mathrm{L}$ (figure 7.10) and between 100-120 (figure 7.11) are shown with $95 \%$ and $99.9 \%$ confidence limits. Table 7.4 can be used to identify centres in these funnel plots.

\section{Haemoglobin in prevalent peritoneal dialysis patients}

The median $\mathrm{Hb}$ of patients on PD in the UK in 2015 was $112 \mathrm{~g} / \mathrm{L}$ (IQR 103-120, table 7.5). For PD patients $81 \%$ had a $\mathrm{Hb} \geqslant 100 \mathrm{~g} / \mathrm{L}$. Figure 7.12 shows the median $\mathrm{Hb}$ in PD patients by centre. Figure 7.13 shows the proportion of patients by centre with $\mathrm{Hb}$ within the Renal Association guideline range (100-120 g/L) and

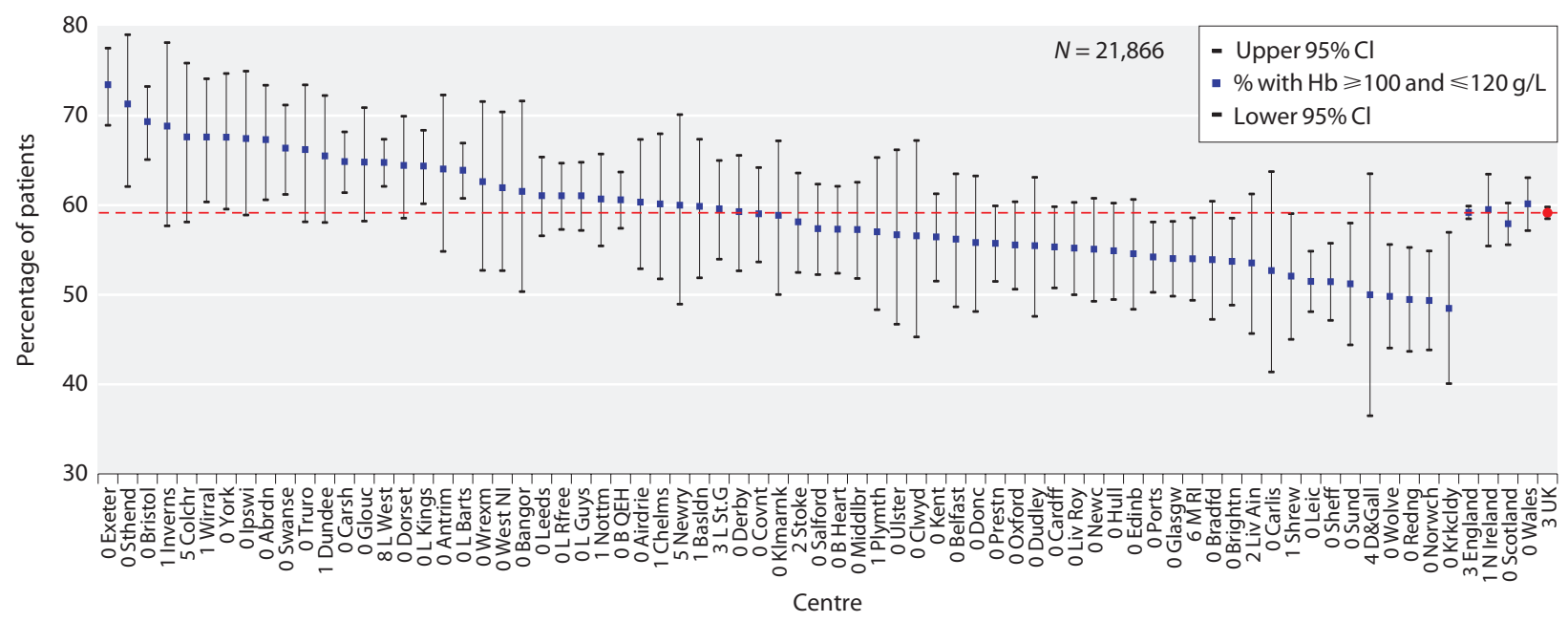

Fig. 7.8. Percentage of $\mathrm{HD}$ patients with $\mathrm{Hb} \geqslant 100 \mathrm{~g} / \mathrm{L}$ and $\leqslant 120 \mathrm{~g} / \mathrm{L}$ by centre in 2015 


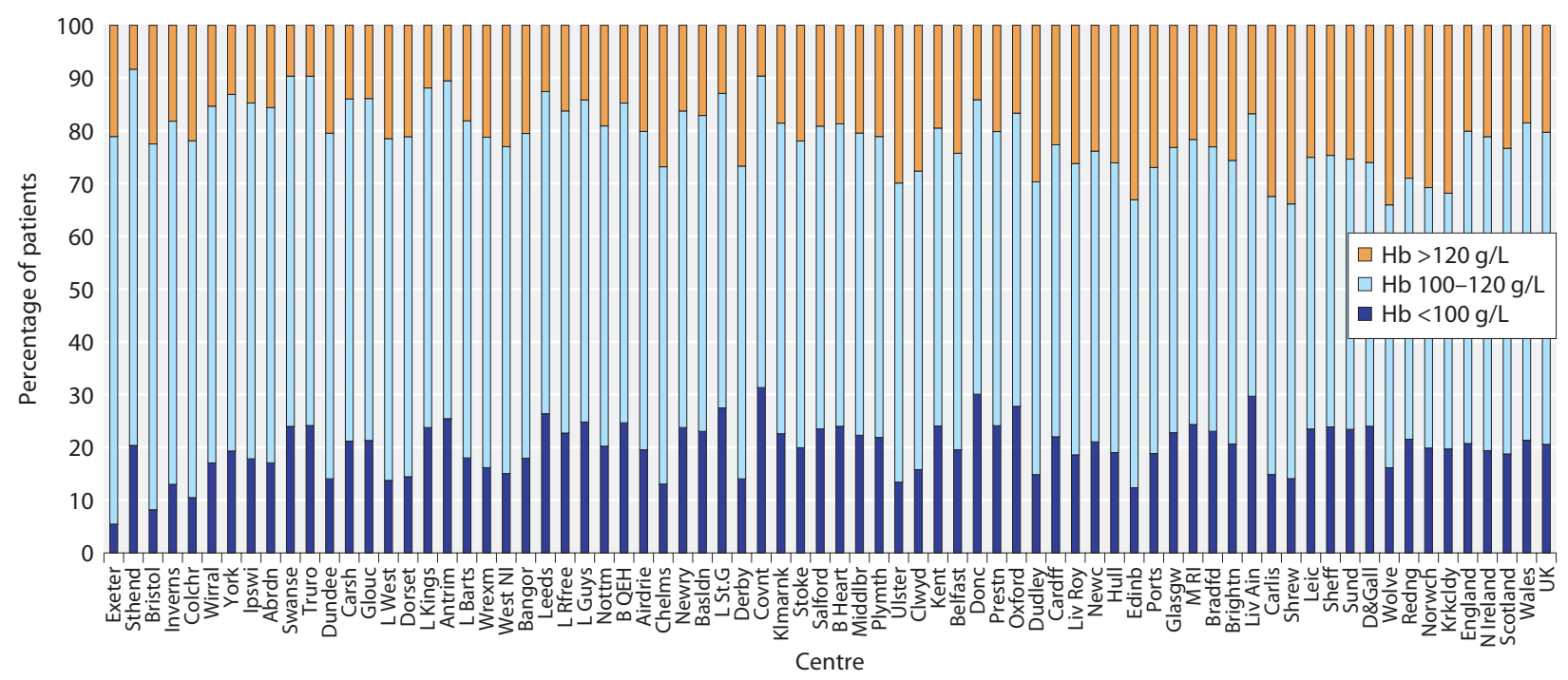

Fig. 7.9. Distribution of haemoglobin in patients treated with HD by centre in 2015

figure 7.14 shows the distribution of $\mathrm{Hb}$ within, above and below this range.

Figures 7.15 and 7.16 are funnel plots showing the percentage of PD patients by centre in 2015 with $\mathrm{Hb} \geqslant 100 \mathrm{~g} / \mathrm{L}$ and $\mathrm{Hb} \geqslant 100 \mathrm{~g} / \mathrm{L}$ and $\leqslant 120 \mathrm{~g} / \mathrm{L}$ respectively.

\section{Relationship between $\mathrm{Hb}$ in incident and prevalent dialysis} patients

The relationship between the percentage of incident and prevalent patients with $\mathrm{Hb} \geqslant 100 \mathrm{~g} / \mathrm{L}$ is shown in figure 7.17. As expected, all centres had a higher

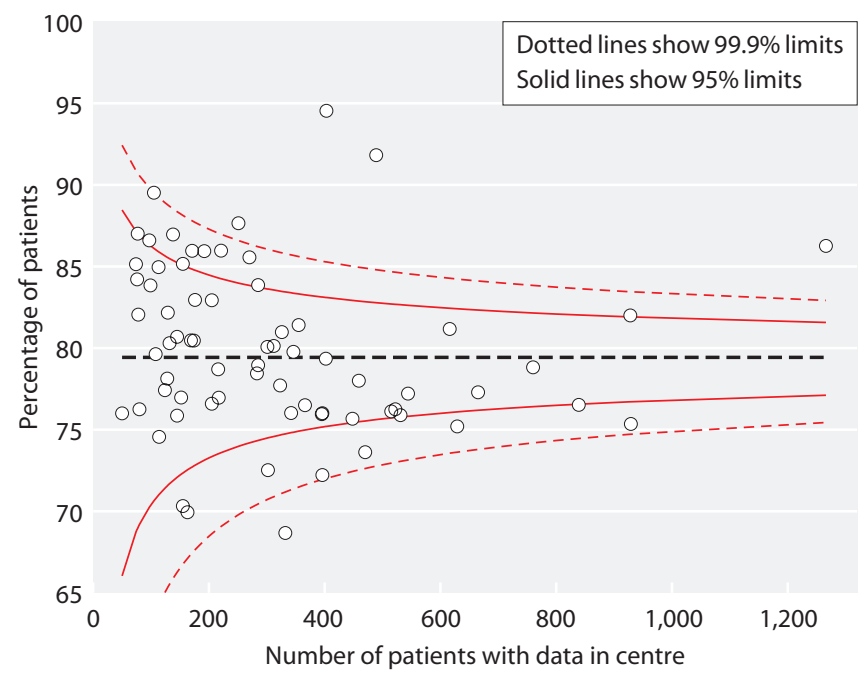

Fig. 7.10. Funnel plot of percentage of $\mathrm{HD}$ patients with $\mathrm{Hb}$ $\geqslant 100 \mathrm{~g} / \mathrm{L}$ by centre in 2015

Anaemia Management in UK dialysis patients percentage of prevalent patients achieving a $\mathrm{Hb}$ $\geqslant 100 \mathrm{~g} / \mathrm{L}$ than of incident patients.

Changes in achievement of $\mathrm{Hb} \geqslant 100 \mathrm{~g} / \mathrm{L}$ by year of start in both incident and prevalent patients is shown in figure 7.18. This shows a continuing fall in the proportion of patients achieving a $\mathrm{Hb} \geqslant 100 \mathrm{~g} / \mathrm{L}$ over the last decade.

\section{Ferritin in prevalent haemodialysis patients}

The median and IQR for serum ferritin for patients treated with $\mathrm{HD}$ are shown in figure 7.19. The percentages with serum ferritin $\geqslant 100 \mu \mathrm{g} / \mathrm{L},>200 \mu \mathrm{g} / \mathrm{L}$ to

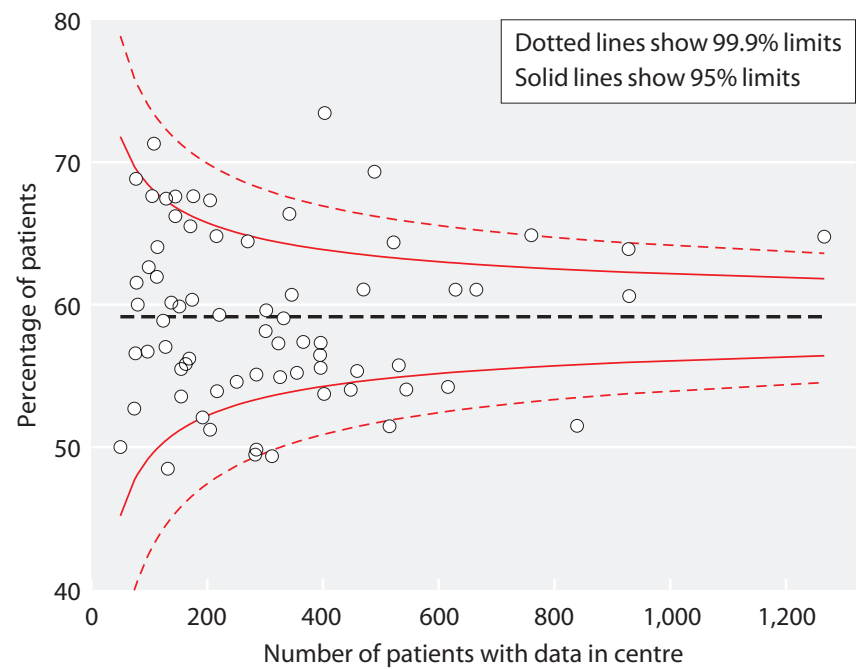

Fig. 7.11. Funnel plot of percentage of $\mathrm{HD}$ patients with $\mathrm{Hb}$ $\geqslant 100 \mathrm{~g} / \mathrm{L}$ and $\leqslant 120 \mathrm{~g} / \mathrm{L}$ by centre in 2015

Nephron 2017;137(suppl1):165-188 


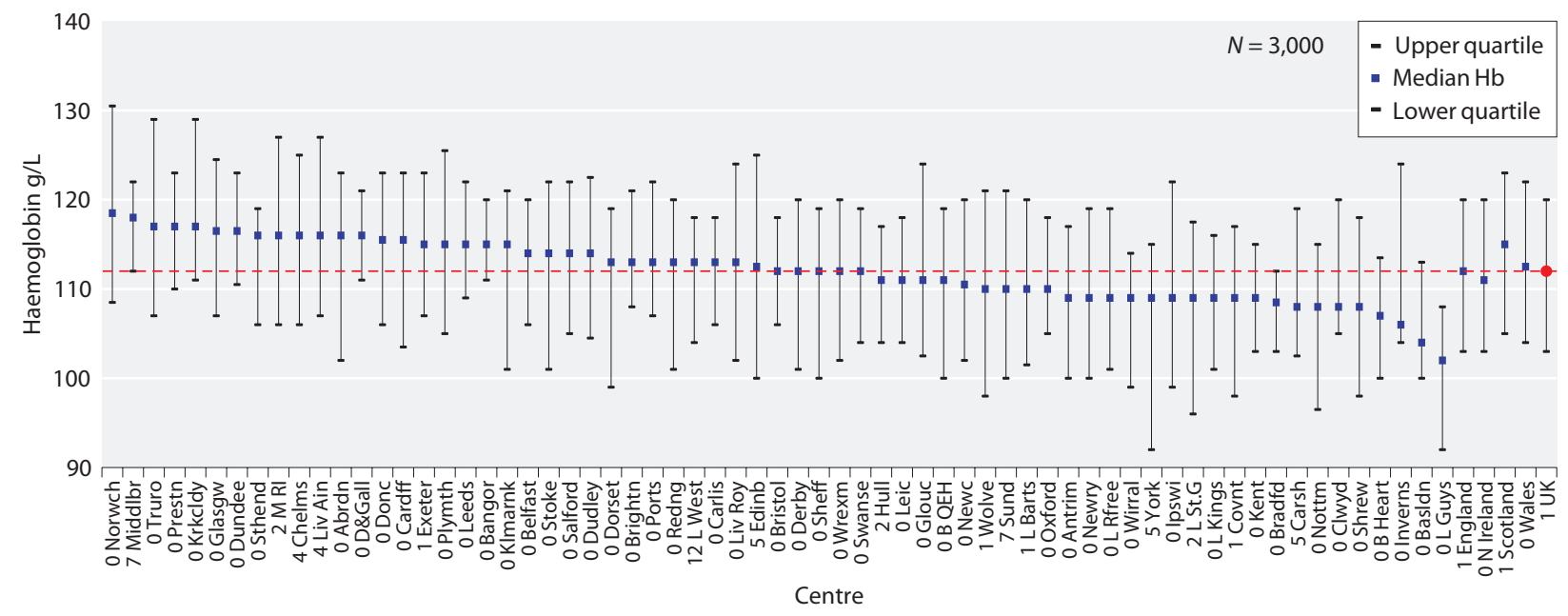

Fig. 7.12. Median haemoglobin in patients treated with PD by centre in 2015

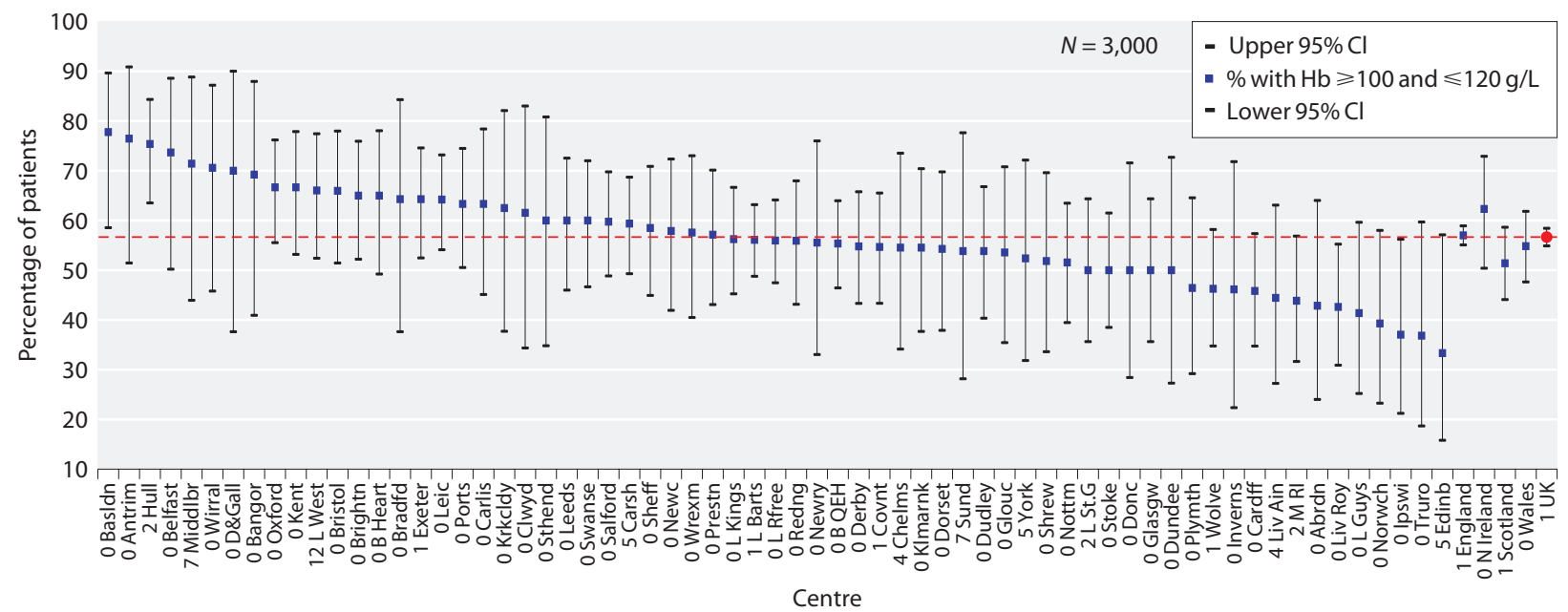

Fig. 7.13. Percentage of $P D$ patients with $\mathrm{Hb} \geqslant 100 \mathrm{~g} / \mathrm{L}$ and $\leqslant 120 \mathrm{~g} / \mathrm{L}$ by centre in 2015

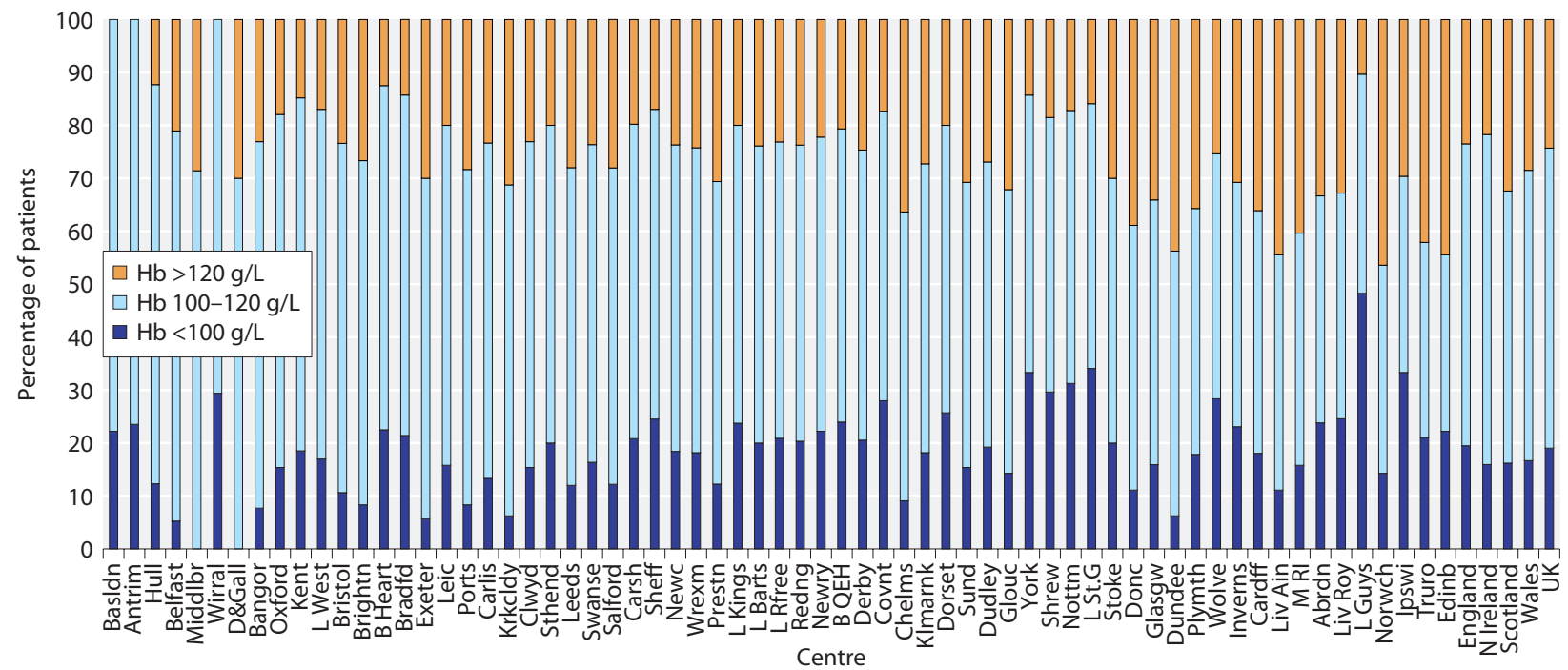

Fig. 7.14. Distribution of haemoglobin in patients treated with PD by centre in 2015 


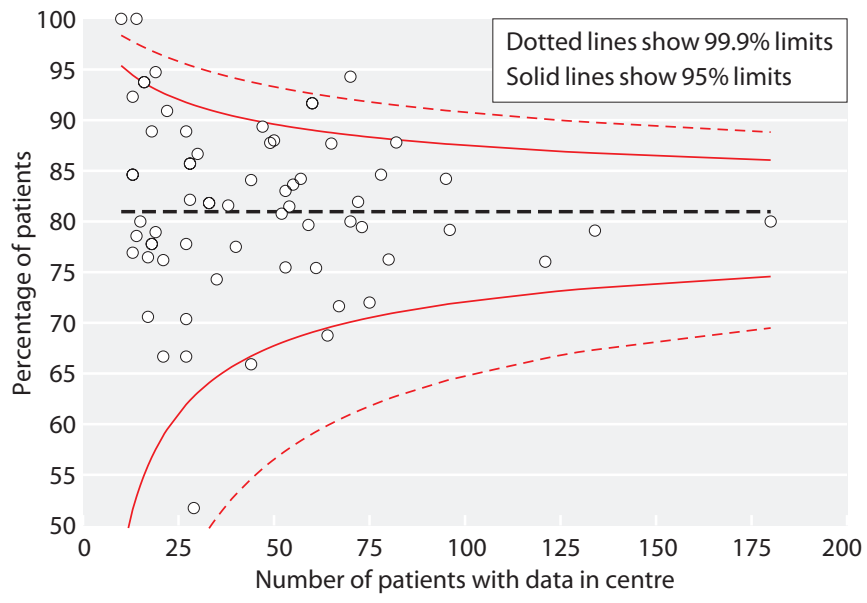

Fig. 7.15. Funnel plot of percentage of $\mathrm{PD}$ patients with $\mathrm{Hb}$ $\geqslant 100 \mathrm{~g} / \mathrm{L}$ by centre in 2015

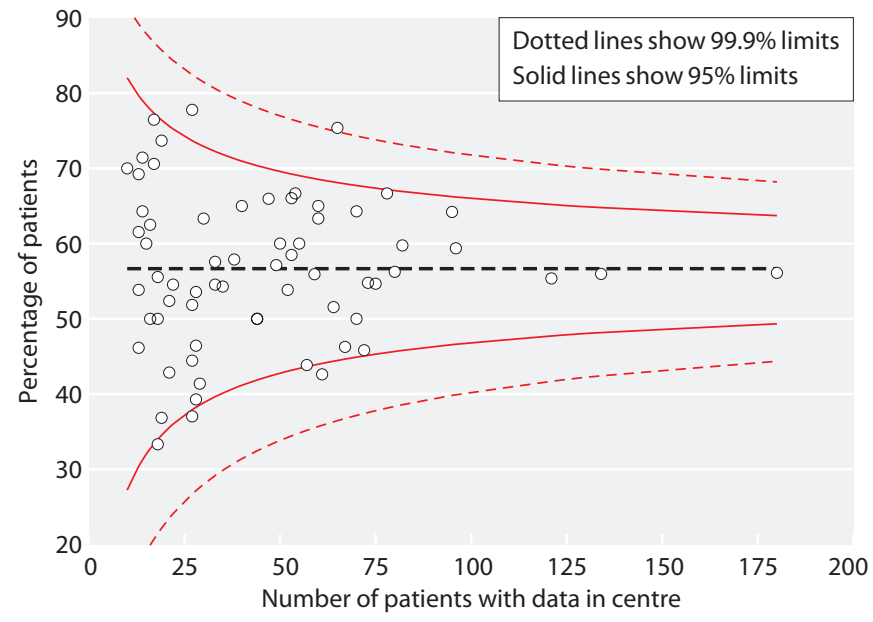

Fig. 7.16. Funnel plot of percentage of $\mathrm{PD}$ patients with $\mathrm{Hb}$ $\geqslant 100 \mathrm{~g} / \mathrm{L}$ and $\leqslant 120 \mathrm{~g} / \mathrm{L}$ by centre in 2015

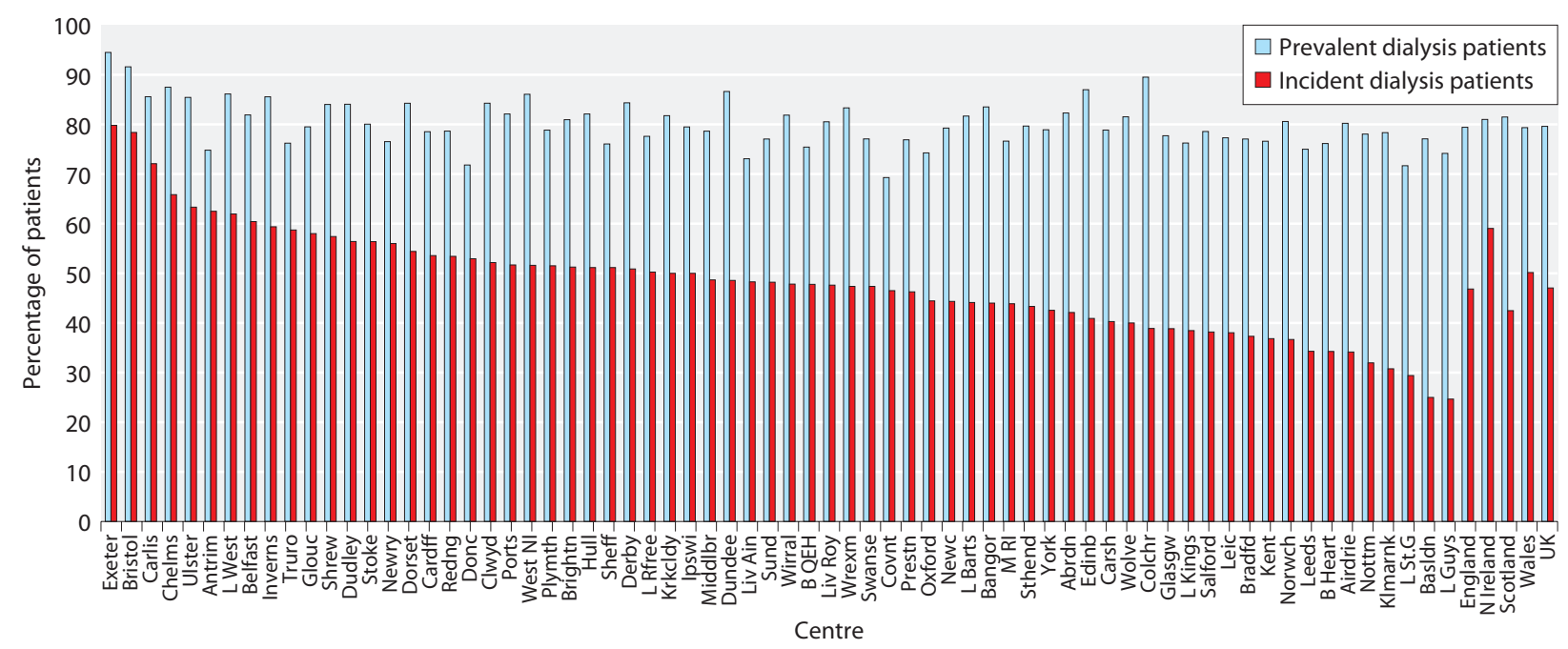

Fig. 7.17. Percentage of incident and prevalent dialysis patients with $\mathrm{Hb} \geqslant 100 \mathrm{~g} / \mathrm{L}$ by centre in 2015

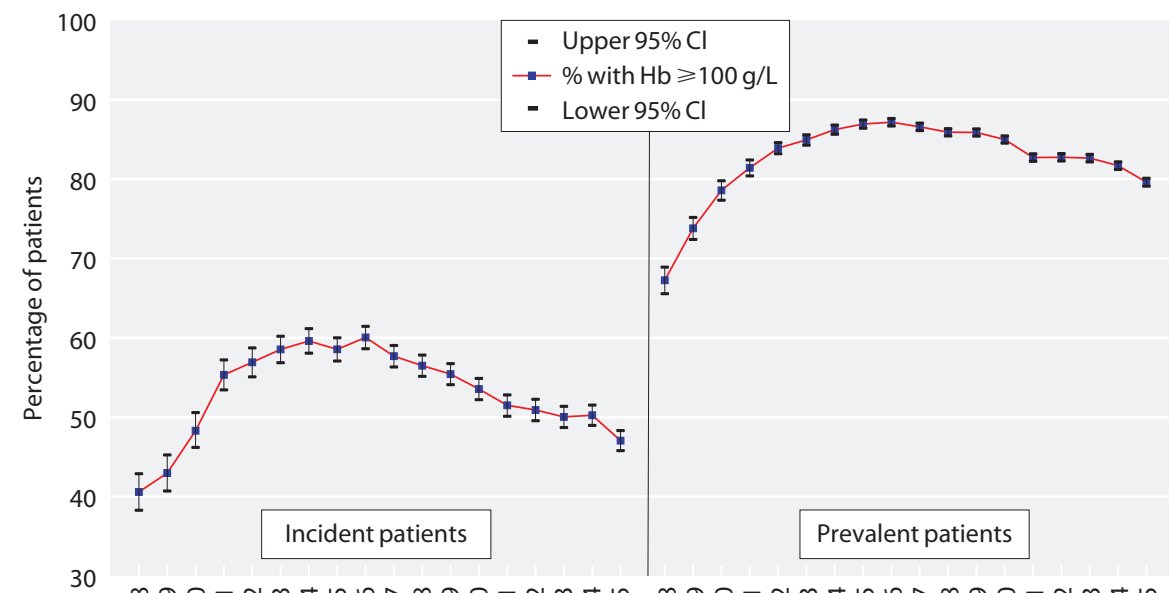

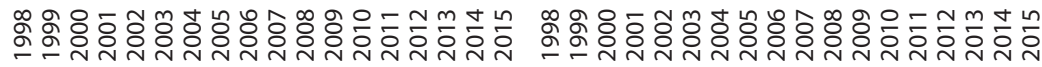
Year
Fig. 7.18. Percentage of incident and prevalent dialysis patients (1998-2015) with $\mathrm{Hb} \geqslant 100 \mathrm{~g} / \mathrm{L}$ 


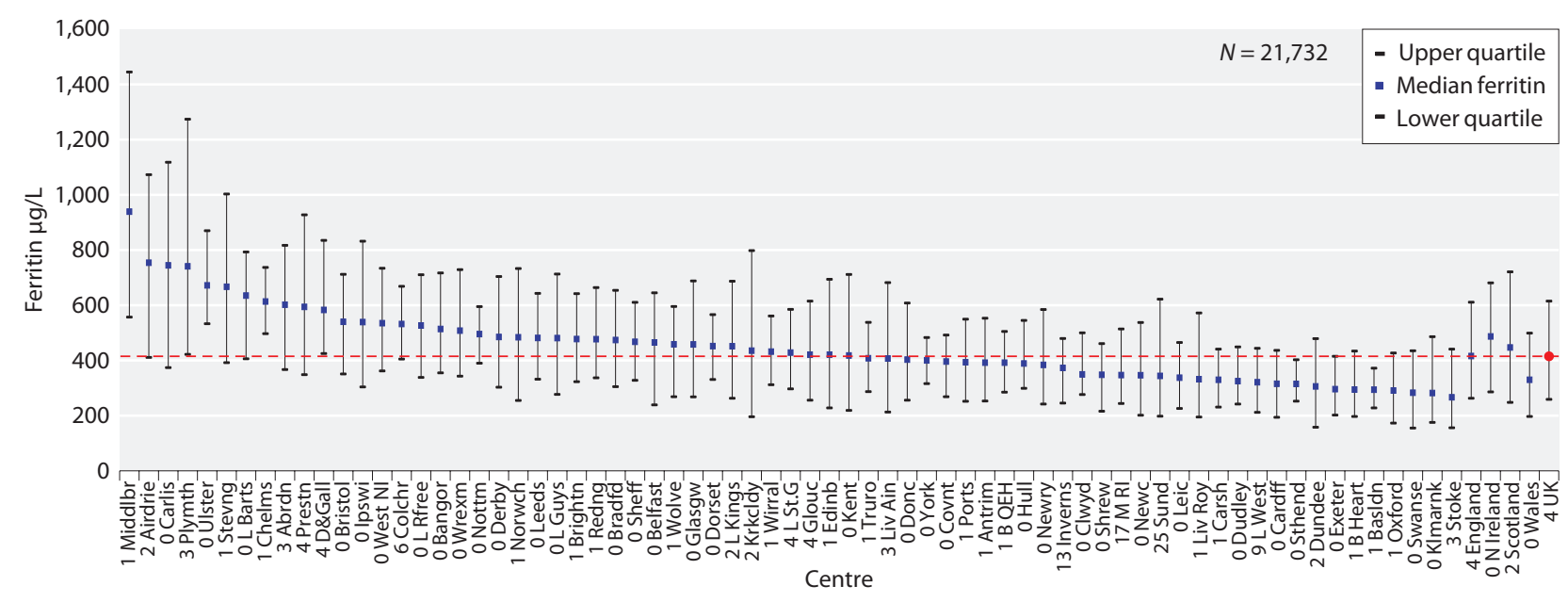

Fig. 7.19. Median ferritin in patients treated with HD by centre in 2015

$\leqslant 500 \mu \mathrm{g} / \mathrm{L}$, and $\geqslant 800 \mu \mathrm{g} / \mathrm{L}$ are shown in figures 7.20 , 7.21 and 7.22 respectively. The median serum ferritin in HD patients was $415 \mu \mathrm{g} / \mathrm{L}$ with $94 \%$ of $\mathrm{HD}$ patients achieving a serum ferritin $\geqslant 100 \mu \mathrm{g} / \mathrm{L}$.

\section{Ferritin in prevalent peritoneal dialysis patients}

The median and IQR for serum ferritin for patients treated with $\mathrm{PD}$ are shown in figure 7.23. The percentages with serum ferritin $\geqslant 100 \mu \mathrm{g} / \mathrm{L},>100 \mu \mathrm{g} / \mathrm{L}$ to $\leqslant 500 \mu \mathrm{g} / \mathrm{L}$, and $\geqslant 800 \mu \mathrm{g} / \mathrm{L}$ are shown in figures 7.24, 7.25 and 7.26 respectively. The median serum ferritin in PD patients was $295 \mu \mathrm{g} / \mathrm{L}$ with $88 \%$ of PD patients achieving a serum ferritin $\geqslant 100 \mu \mathrm{g} / \mathrm{L}$.

\section{Erythropoiesis stimulating agents in prevalent} haemodialysis patients

The median dose of ESA for prevalent HD patients in England, Wales and Northern Ireland was 7,500 IU/week with wide variation between centres from 4,833 IU/week (York) to 13,267 IU/week (Newcastle) (table 7.4). There was very little correlation between median ESA dose and either median $\mathrm{Hb}$ (figure 7.27) or compliance with $\mathrm{Hb} 100-120 \mathrm{~g} / \mathrm{L}$ (figure 7.28). For these analyses only patients with both $\mathrm{Hb}$ and ESA data were included.

\section{Erythropoiesis stimulating agents in prevalent peritoneal dialysis patients}

The median dose of ESA for prevalent PD patients in England, Wales and Northern Ireland was 4,000 IU/week (table 7.5).

\section{ESA prescription and association with achieved haemoglobin}

Figures 7.9 and 7.14 show the distribution of $\mathrm{Hb}$ concordance with the RA guideline $(100-120 \mathrm{~g} / \mathrm{L})$. Not all patients with $\mathrm{Hb}>120 \mathrm{~g} / \mathrm{L}$ are receiving ESA. The

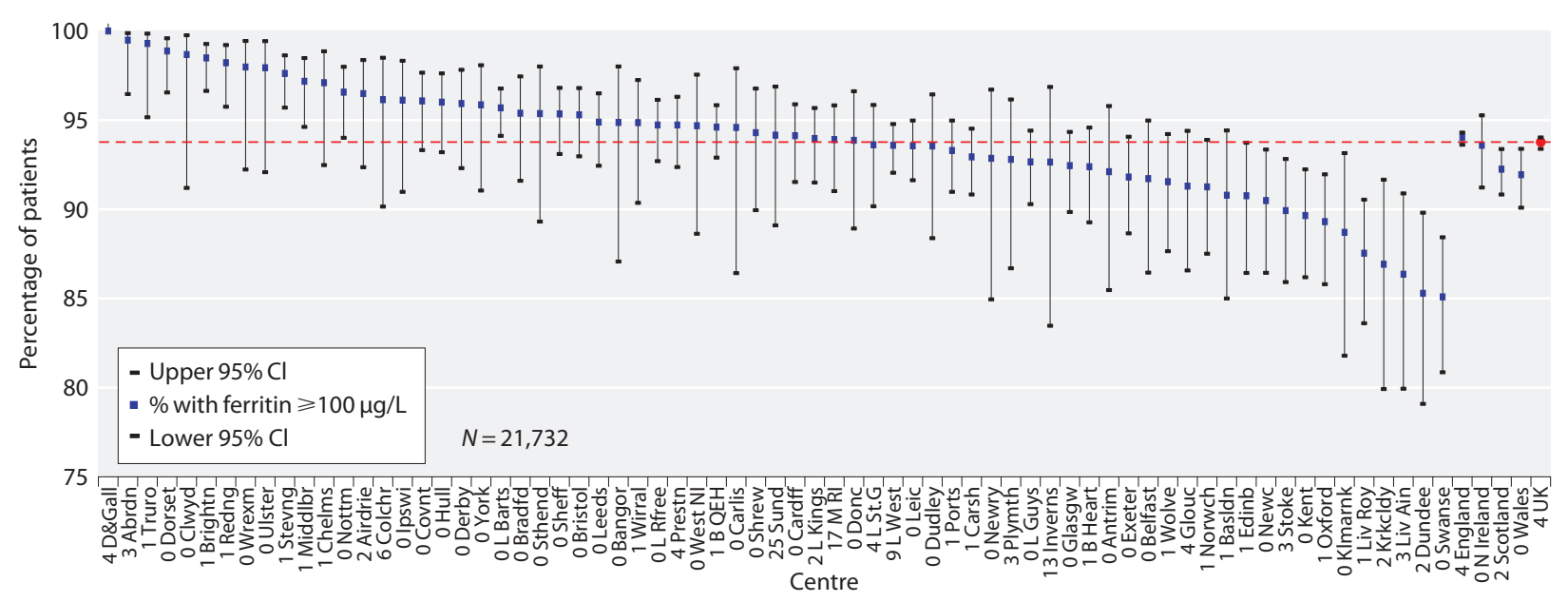

Fig. 7.20. Percentage of HD patients with ferritin $\geqslant 100 \mu \mathrm{g} / \mathrm{L}$ by centre in 2015 


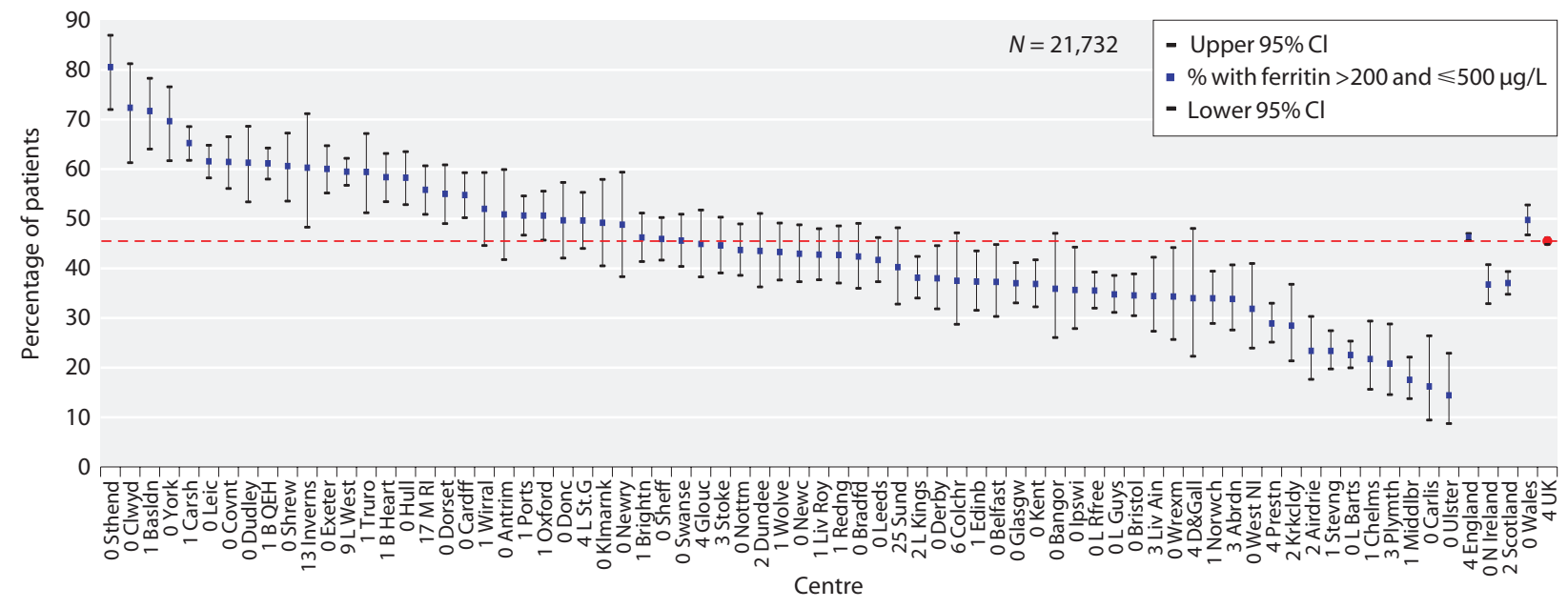

Fig. 7.21. Percentage of HD patients with ferritin $>200$ and $\leqslant 500 \mu \mathrm{g} / \mathrm{L}$ by centre in 2015

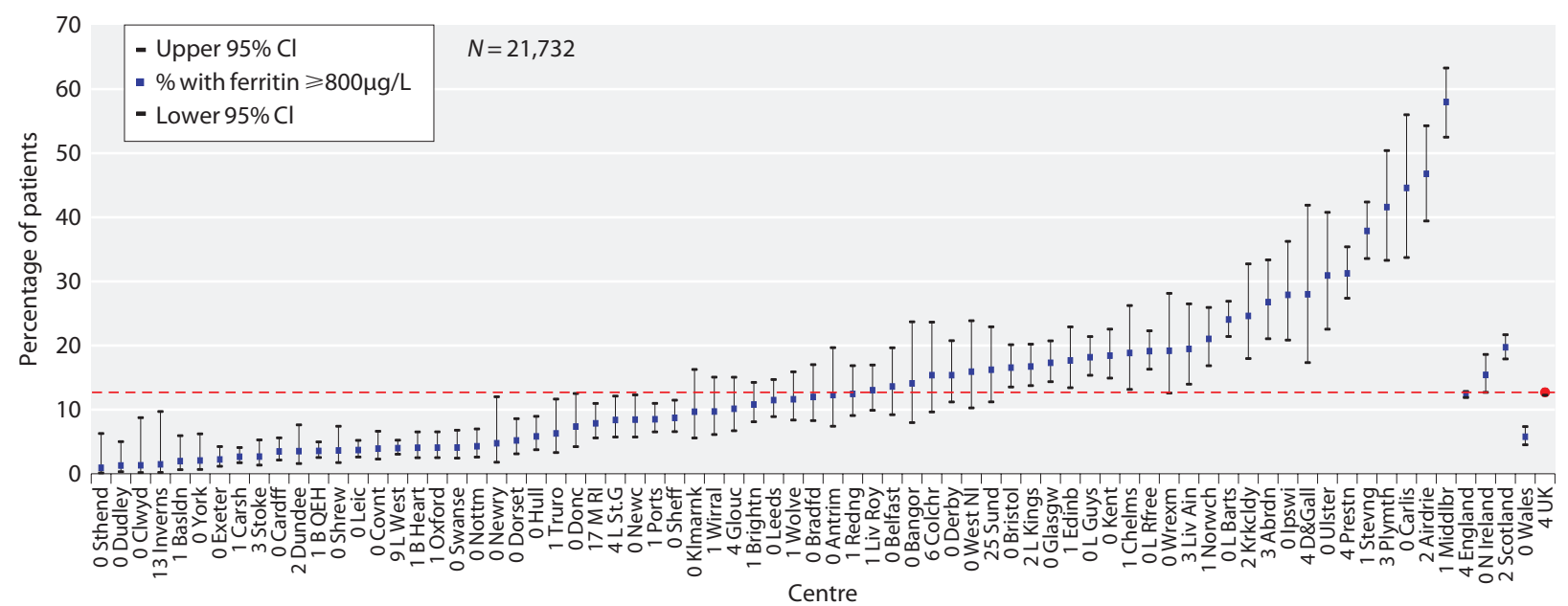

Fig. 7.22. Percentage of HD patients with ferritin $\geqslant 800 \mu \mathrm{g} / \mathrm{L}$ by centre in 2015

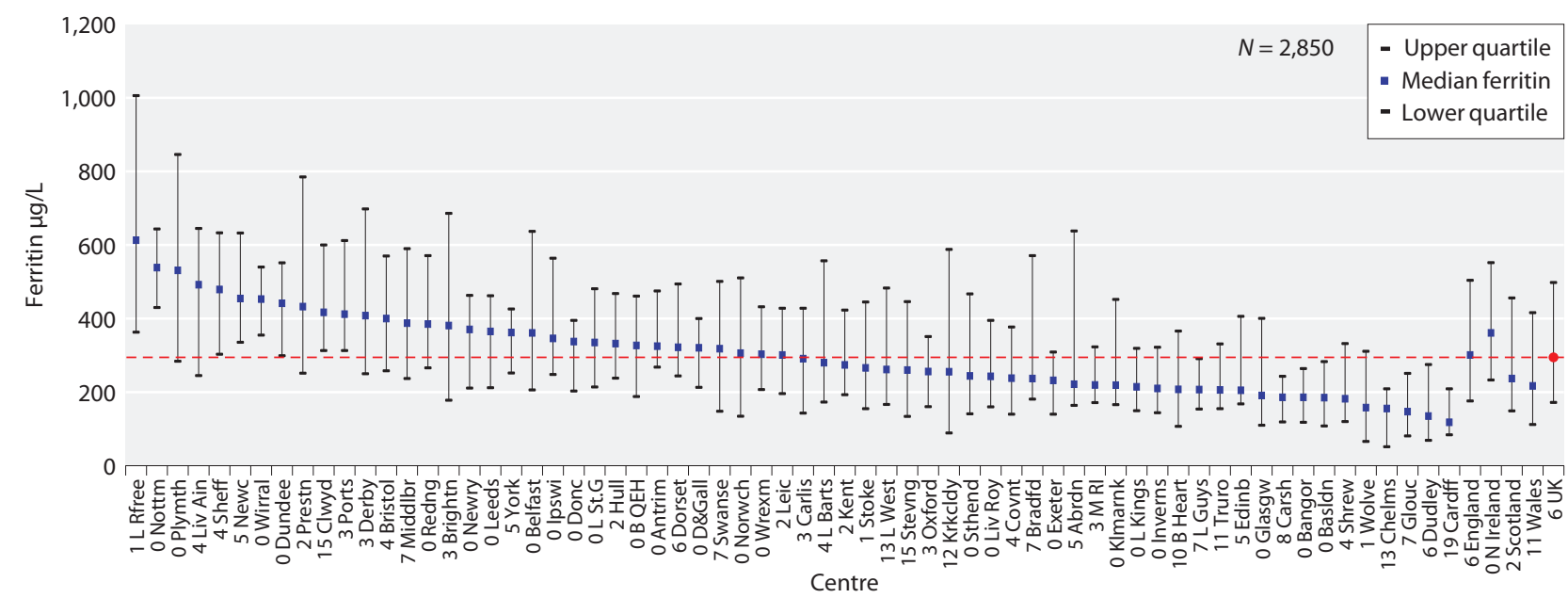

Fig. 7.23. Median ferritin in patients treated with PD by centre in 2015 


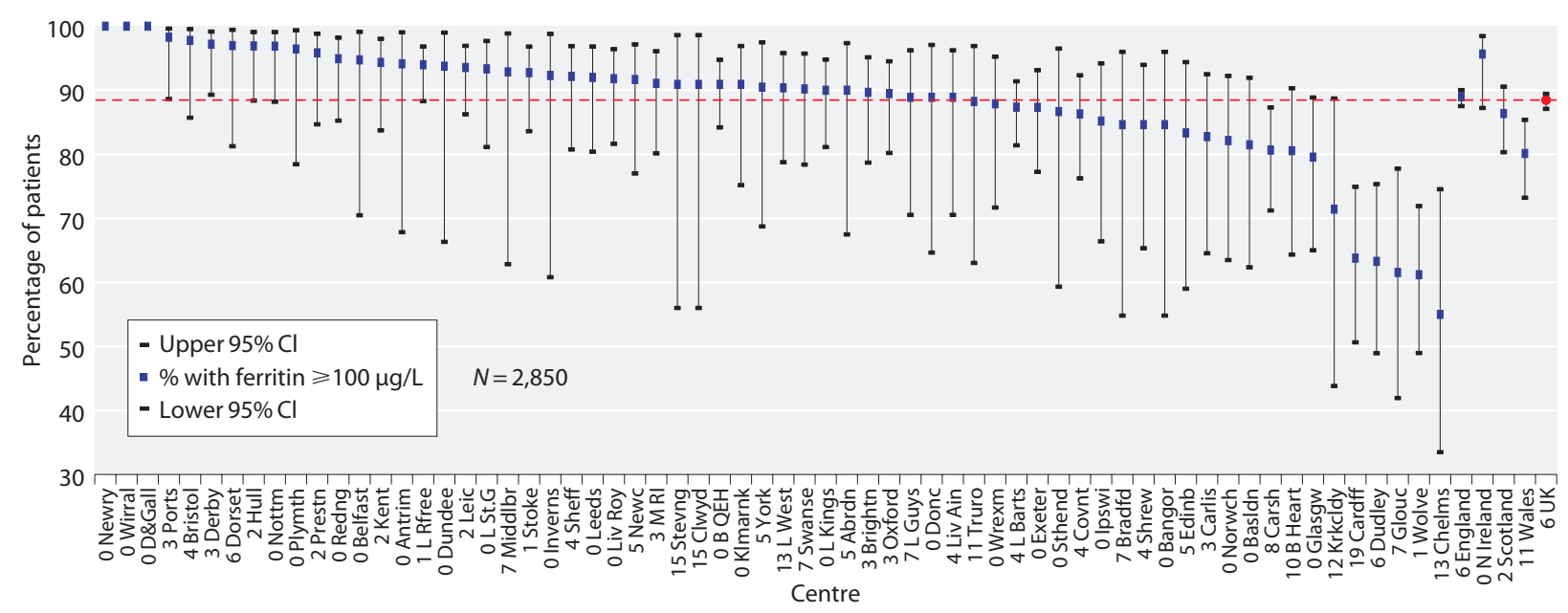

Fig. 7.24. Percentage of PD patients with ferritin $\geqslant 100 \mu \mathrm{g} / \mathrm{L}$ by centre in 2015

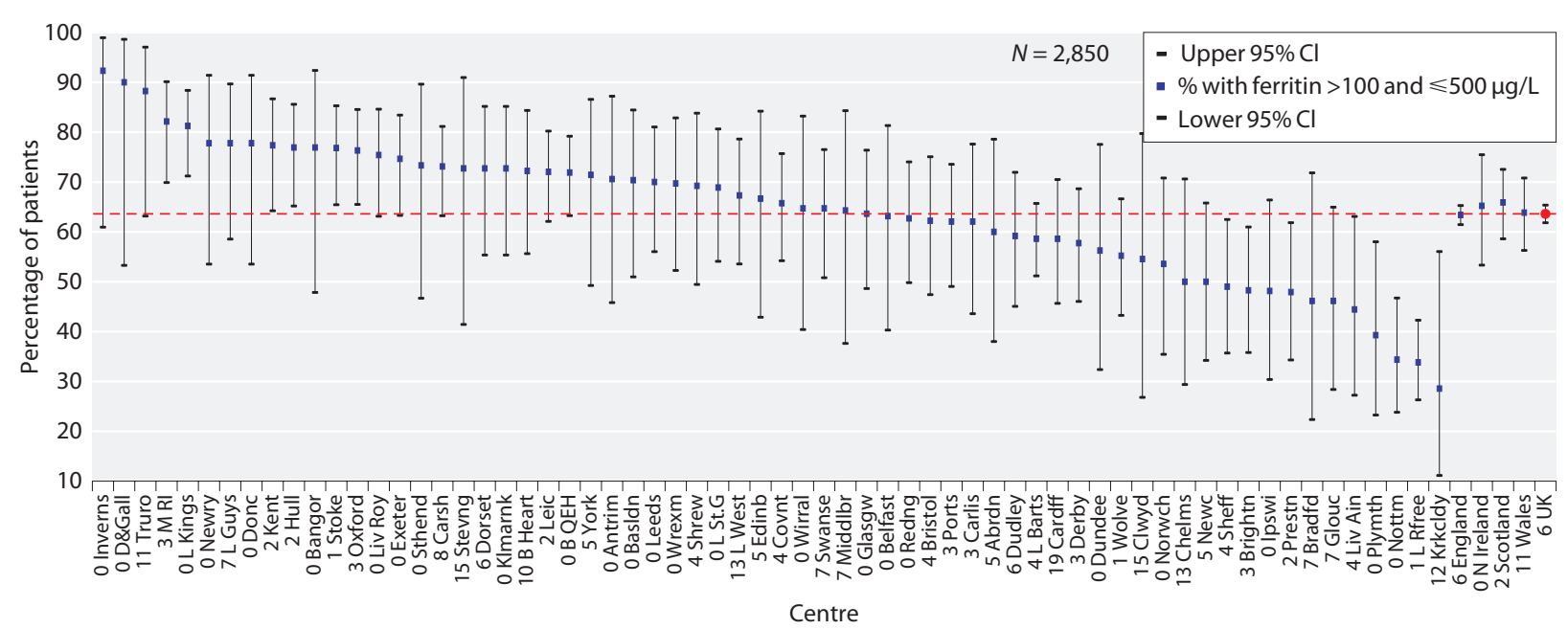

Fig. 7.25. Percentage of PD patients with ferritin $>100$ and $\leqslant 500 \mu \mathrm{g} / \mathrm{L}$ by centre in 2015

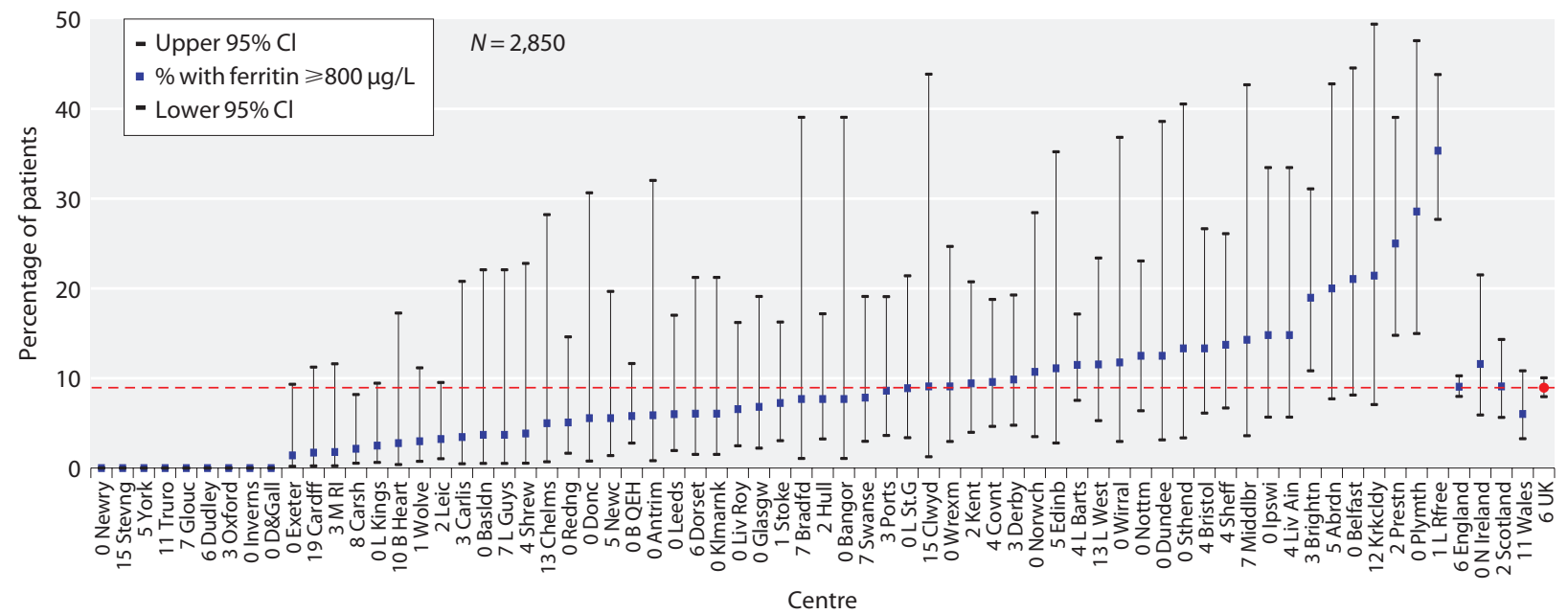

Fig. 7.26. Percentage of PD patients with ferritin $\geqslant 800 \mu \mathrm{g} / \mathrm{L}$ by centre in 2015 


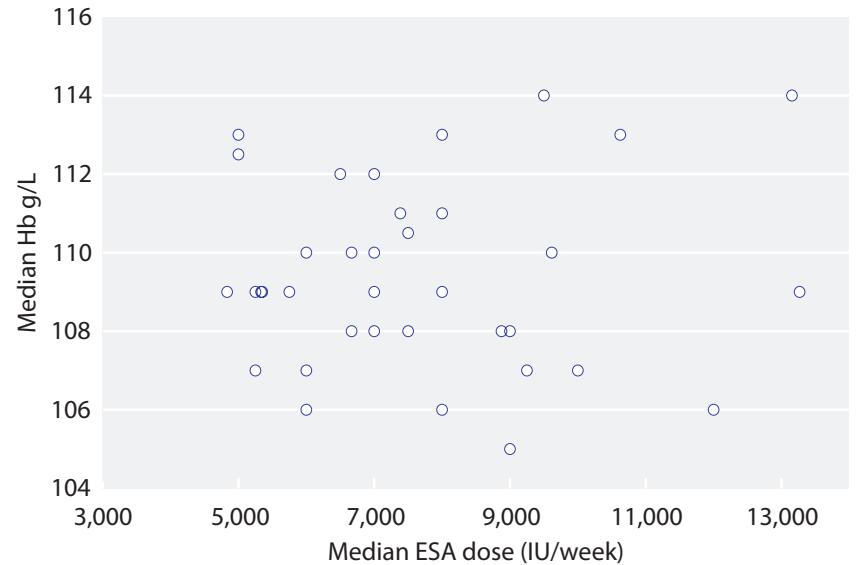

Fig. 7.27. Median Hb versus median ESA dose in HD patients on ESA, by centre in 2015

consensus was that these patients should not be included in the group of patients not meeting this target. There are two reasons: first, the high $\mathrm{Hb}$ remains largely outside the control of the clinician; secondly, the trials suggesting it may be detrimental to achieve a high $\mathrm{Hb}$ in renal patients were based upon patients treated with ESAs [6-8]. Figures 7.29 and 7.30 therefore show the percentages of $\mathrm{HD}$ and $\mathrm{PD}$ patients in each centre whose $\mathrm{Hb}$ lies below, within or above the RA guideline range. For those patients with $\mathrm{Hb}>120 \mathrm{~g} / \mathrm{L}$ it also differentiates between those receiving, or not, ESAs. In centres with useable ESA data, $20.0 \%$ of $\mathrm{HD}$ patients had a $\mathrm{Hb}$ $>120 \mathrm{~g} / \mathrm{L}$ and $4.9 \%$ had a $\mathrm{Hb}>120 \mathrm{~g} / \mathrm{L}$ and were not receiving ESAs. For PD patients $21.3 \%$ had a $\mathrm{Hb}$

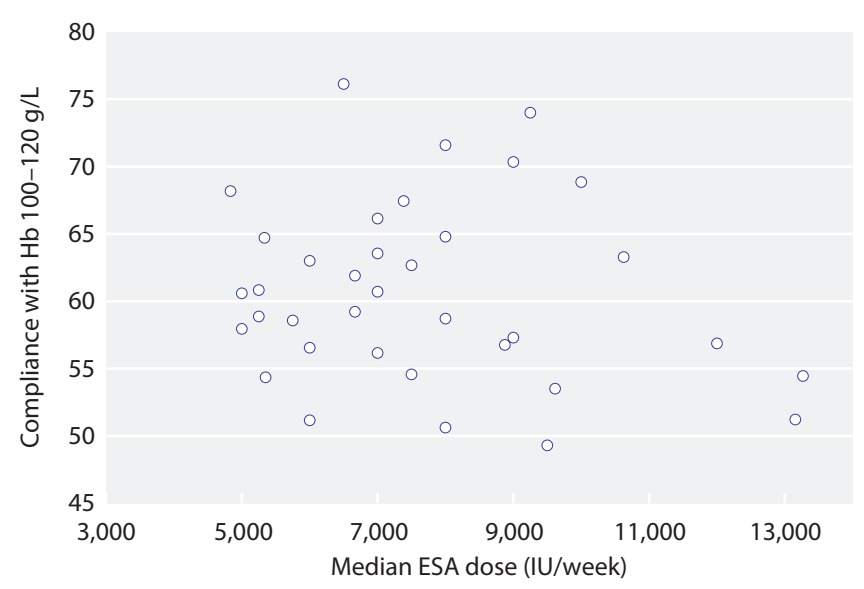

Fig. 7.28. Compliance with $\mathrm{Hb} 100-120$ g/L versus median ESA dose in HD patients on ESA, by centre in 2015

$>120 \mathrm{~g} / \mathrm{L}$ and $11.8 \%$ had a $\mathrm{Hb}>120 \mathrm{~g} / \mathrm{L}$ and were not receiving ESAs.

\section{ESA prescription: age and modality associations}

The proportion of patients on ESA was higher for HD (88\%) than for PD (69\%). This difference was maintained across all age groups (figure 7.31). The proportion of patients with $\mathrm{Hb} \geqslant 100 \mathrm{~g} / \mathrm{L}$ without requiring an ESA is shown (by age group and modality) in figure 7.32 .

\section{ESAs and time on renal replacement therapy}

The percentage of patients on ESA by time on RRT and dialysis modality is shown in figure 7.33 . This is a

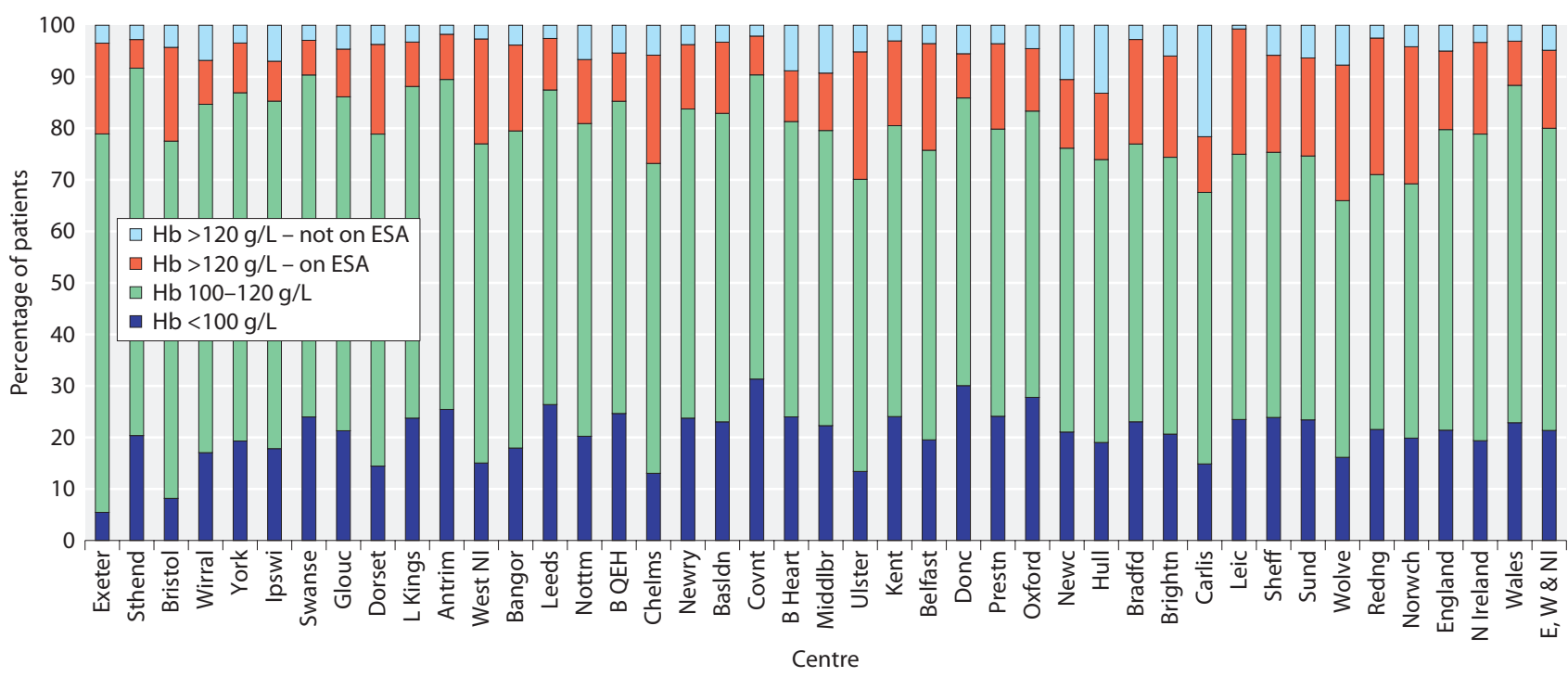

Fig. 7.29. Distribution of haemoglobin in patients treated with $\mathrm{HD}$ and the proportion of patients with $\mathrm{Hb}>120 \mathrm{~g} / \mathrm{L}$ receiving ESA by centre in 2015 


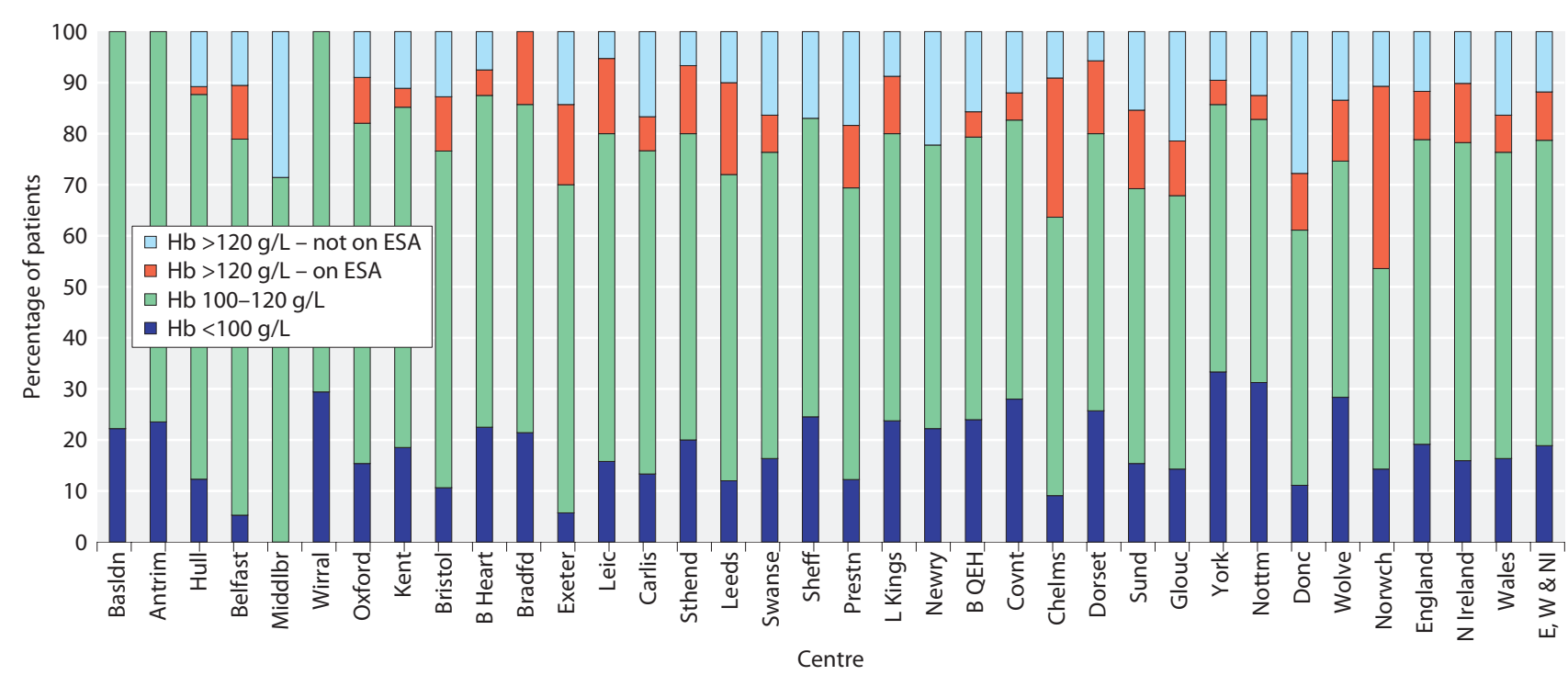

Fig. 7.30. Distribution of haemoglobin in patients treated with $\mathrm{PD}$ and the proportion of patients with $\mathrm{Hb}>120 \mathrm{~g} / \mathrm{L}$ receiving ESA by centre in 2015

cross-sectional analysis of patients at the end of 2015. Patients who had previously changed RRT modality were included in the analysis. The proportion of PD patients receiving ESA rises with duration of RRT from $65 \%$ after $3-12$ months to $84 \%$ after 10 or more years.

\section{Resistance to ESA therapy}

The Renal Association guidelines define resistance to ESA therapy as 'failure to reach the target $\mathrm{Hb}$ level despite sc epoetin dose $>300 \mathrm{IU} / \mathrm{kg} /$ week $(450 \mathrm{IU} / \mathrm{kg} /$ week iv epoetin) or darbepoetin dose $>1.5 \mathrm{mcg} / \mathrm{kg} /$ week' [4]. Figure 7.34 shows the frequency distribution of weekly ESA dose adjusted for weight by treatment modality. Centres included in this analysis were restricted to those with good completeness for weight $(>75 \%)$ and ESA data. Thirty three centres were included for HD data and 20 centres for PD. The prevalence of PD patients receiving over $300 \mathrm{IU} / \mathrm{kg} /$ week was $1.6 \%$ with $6.1 \%$ of $\mathrm{HD}$ patients receiving more than $300 \mathrm{IU} / \mathrm{kg} /$ week and $1.1 \%$ more than $450 \mathrm{IU} / \mathrm{kg} /$ week.

\section{Success with guideline compliance}

The percentage of prevalent dialysis patients achieving $\mathrm{a} \mathrm{Hb} \geqslant 100 \mathrm{~g} / \mathrm{L}$ by year $(1998-2015)$ is shown in

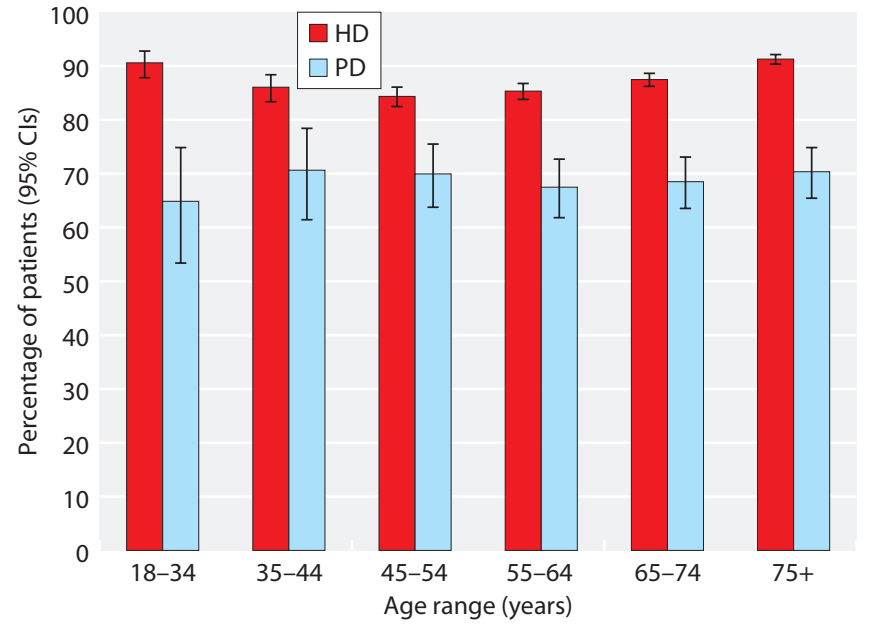

Fig. 7.31. Percentage of dialysis patients on ESA, by age group and treatment modality in 2015

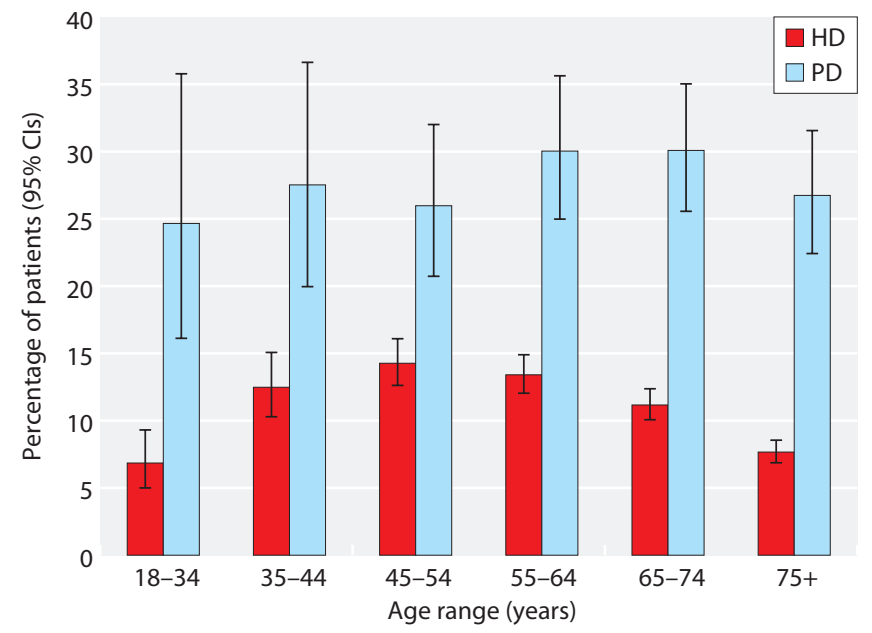

Fig. 7.32. Percentage of whole cohort (2015) who were not on ESA and had $\mathrm{Hb} \geqslant 100 \mathrm{~g} / \mathrm{L}$, by age group and treatment modality 


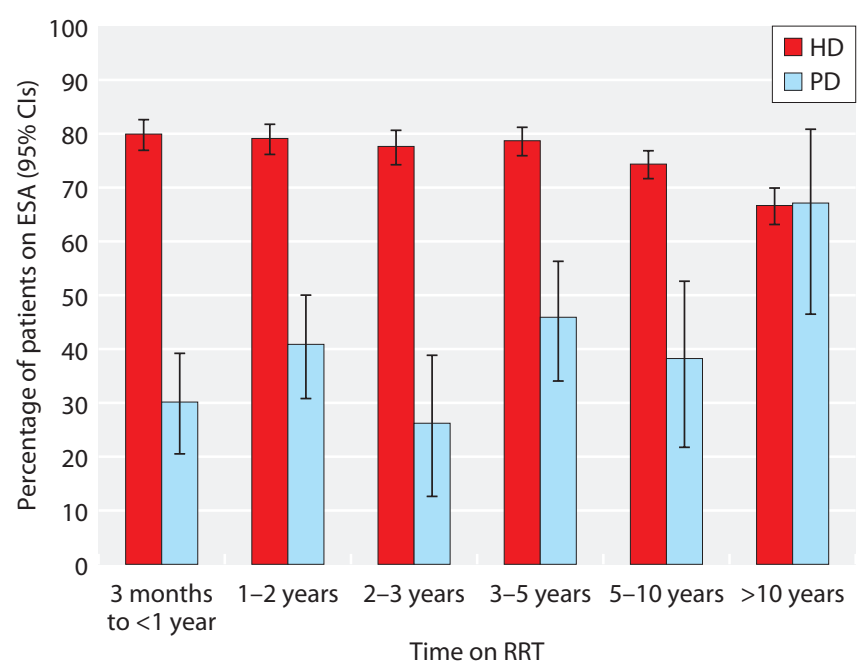

Fig. 7.33. Percentage of patients on ESA by time on RRT in 2015

figure 7.35. This has shown a gradual fall in achievement of this guideline over the last decade.

Table 7.6 shows that the percentage of all patients treated with an ESA and having $\mathrm{Hb}>120 \mathrm{~g} / \mathrm{L}$ ranged between $6-27 \%$ for $\mathrm{HD}$ and between $0-27 \%$ for PD.

Table 7.7 shows the percentage completeness for ESA type, dose, route and frequency for centres reporting ESA data. Even for this group of centres which is already restricted to those with useable ESA data, completeness of frequency and administration route average below $50 \%$. Roughly half of the centres have very good completeness for these items and the other half did not submit at all.

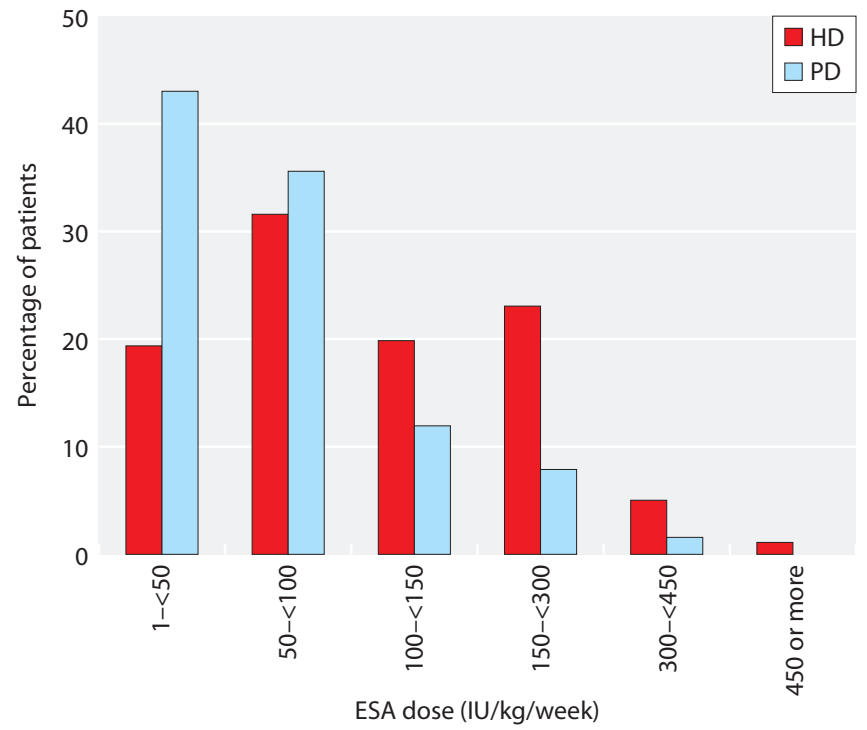

Fig. 7.34. Frequency distribution of mean weekly ESA dose corrected for weight in 2015

\section{Discussion}

Anaemia is one of the major comorbidities associated with chronic kidney disease. This is largely caused by a reduction (absolute or relative) in erythropoietin production, though there are a number of other contributory factors including (absolute or relative) iron deficiency; inflammatory processes related to underlying kidney disease or other comorbidities; inflammatory processes related to dialysis; blood loss (CKD-associated platelet dysfunction, frequent phlebotomy, dialysis-associated

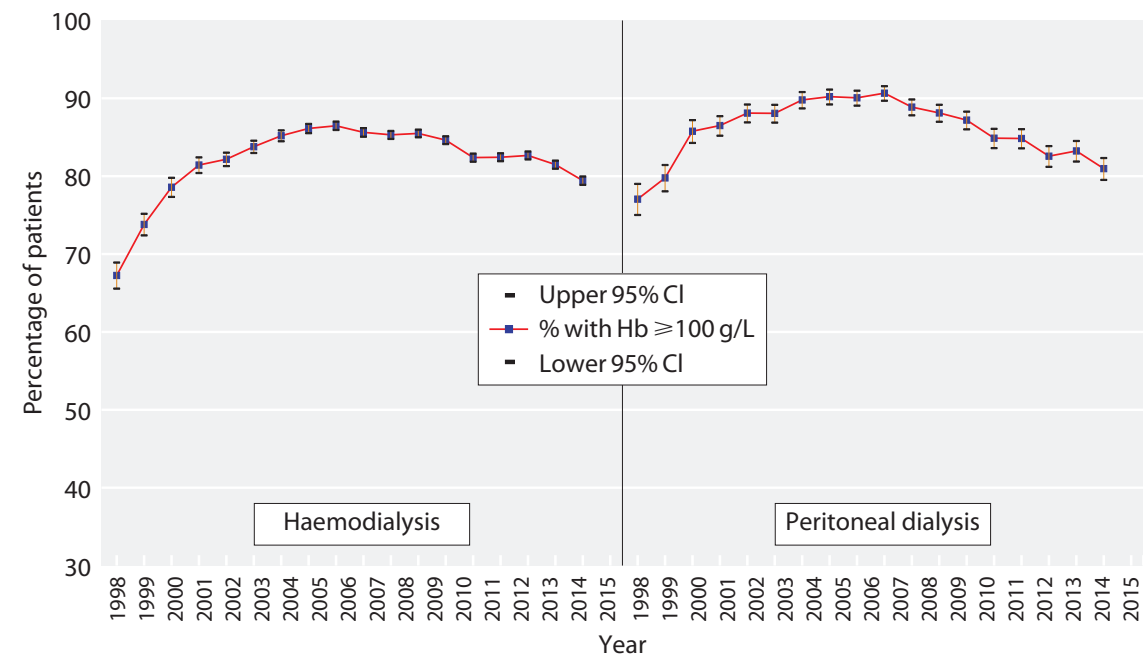

Fig. 7.35. Percentage of prevalent $\mathrm{HD}$ and PD patients (1998-2015) with $\mathrm{Hb} \geqslant 100 \mathrm{~g} / \mathrm{L}$ 
Table 7.6. Percentage of patients with $\mathrm{Hb}>120 \mathrm{~g} / \mathrm{L}$ and on ESA and percentage of patients with serum ferritin $<100 \mu \mathrm{g} / \mathrm{L}$ and on ESA, by modality

\begin{tabular}{|c|c|c|c|c|}
\hline \multirow[b]{2}{*}{ Centre } & \multicolumn{2}{|c|}{$\mathrm{HD}$} & \multicolumn{2}{|c|}{$\mathrm{PD}$} \\
\hline & $\begin{array}{c}\% \text { with } \mathrm{Hb}>120 \mathrm{~g} / \mathrm{L} \\
\text { and on ESA }\end{array}$ & $\begin{array}{c}\% \text { with ferr }<100 \mu \mathrm{g} / \mathrm{L} \\
\text { and on ESA }\end{array}$ & $\begin{array}{c}\% \text { with } \mathrm{Hb}>120 \mathrm{~g} / \mathrm{L} \\
\text { and on ESA }\end{array}$ & $\begin{array}{c}\% \text { with ferr }<100 \mu \mathrm{g} / \mathrm{L} \\
\text { and on ESA }\end{array}$ \\
\hline \multicolumn{5}{|l|}{ England } \\
\hline B Heart & 10 & 4 & 5 & 7 \\
\hline B QEH & 9 & 2 & 5 & 0 \\
\hline Brightn & 20 & 1 & & \\
\hline Bristol & 18 & 4 & 11 & 0 \\
\hline Carlis & 11 & 0 & 7 & 4 \\
\hline Chelms & 21 & 2 & 27 & 35 \\
\hline Covnt & 8 & 2 & 5 & 3 \\
\hline Glouc & 9 & 4 & 11 & 15 \\
\hline Hull & 13 & 2 & 2 & 0 \\
\hline Ipswi & 8 & 2 & & \\
\hline Kent & 16 & 9 & 4 & 2 \\
\hline L Kings & 9 & 6 & 11 & 8 \\
\hline Leeds & 10 & 4 & 18 & 2 \\
\hline Leic & 24 & 6 & 15 & 4 \\
\hline Middlbr & 11 & 0 & 0 & 0 \\
\hline Newc & 13 & 5 & & \\
\hline Norwch & 27 & 6 & 36 & 14 \\
\hline Nottm & 12 & 1 & 5 & 0 \\
\hline Wolve & 26 & 4 & 12 & 15 \\
\hline York & 10 & 0 & 5 & 0 \\
\hline \multicolumn{5}{|l|}{ N Ireland } \\
\hline Antrim & 9 & 4 & 0 & 0 \\
\hline Belfast & 21 & 6 & 11 & 6 \\
\hline Newry & 13 & 7 & 0 & 0 \\
\hline Ulster & 25 & 0 & & \\
\hline West NI & 20 & 4 & & \\
\hline \multicolumn{5}{|l|}{ Wales } \\
\hline Bangor & 17 & 4 & & \\
\hline Swanse & 7 & 12 & 7 & 5 \\
\hline England & 15 & 4 & 9 & 5 \\
\hline N Ireland & 18 & 5 & 12 & 3 \\
\hline Wales & 9 & 11 & 7 & 5 \\
\hline $\mathrm{E}, \mathrm{W} \& \mathrm{NI}$ & 15 & 4 & 9 & 5 \\
\hline
\end{tabular}

Blank cells: centres excluded from analyses due to poor data completeness, small numbers with data or incomplete ESA data 
Table 7.7. Percentage completeness for type, dose, route and frequency of administration of ESA

\begin{tabular}{|c|c|c|c|c|c|c|c|c|c|c|}
\hline \multirow[b]{2}{*}{ Centre } & \multicolumn{5}{|c|}{ HD } & \multicolumn{5}{|c|}{$\mathrm{PD}$} \\
\hline & $\begin{array}{l}N \text { on } \\
\text { ESA }\end{array}$ & $\begin{array}{l}\text { \% with } \\
\text { drug } \\
\text { type }\end{array}$ & $\begin{array}{l}\% \text { with } \\
\text { dose }\end{array}$ & $\begin{array}{l}\% \text { with } \\
\text { frequency }\end{array}$ & $\begin{array}{c}\% \text { with } \\
\text { administration } \\
\text { route }\end{array}$ & $\begin{array}{l}N \text { on } \\
\text { ESA }\end{array}$ & $\begin{array}{l}\text { \% with } \\
\text { drug } \\
\text { type }\end{array}$ & $\begin{array}{l}\% \text { with } \\
\text { dose }\end{array}$ & $\begin{array}{l}\% \text { with } \\
\text { frequency }\end{array}$ & $\begin{array}{c}\% \text { with } \\
\text { administration } \\
\text { route }\end{array}$ \\
\hline \multicolumn{11}{|l|}{ England } \\
\hline B Heart & 311 & 100 & 99 & 0 & 0 & 22 & 100 & 100 & 0 & 0 \\
\hline Basldn & 141 & 100 & 100 & 100 & 100 & 24 & 100 & 100 & 100 & 100 \\
\hline Bradfd & 203 & 100 & 100 & 100 & 98 & 12 & 100 & 100 & 100 & 100 \\
\hline Brightn & 333 & 100 & 100 & 0 & 0 & & & & & \\
\hline Bristol & 454 & 100 & 100 & 0 & 0 & 35 & 100 & 100 & 0 & 0 \\
\hline Carlis & 51 & 100 & 100 & 0 & 0 & 19 & 100 & 100 & 0 & 0 \\
\hline Chelms & 128 & 100 & 100 & 99 & 100 & 15 & 100 & 100 & 100 & 100 \\
\hline Exeter & 380 & 100 & 99 & 0 & 0 & 54 & 100 & 100 & 0 & 0 \\
\hline Glouc & 195 & 100 & 0 & 0 & 0 & 17 & 100 & 0 & 0 & 0 \\
\hline Hull & 204 & 100 & 100 & 100 & 100 & 31 & 100 & 90 & 90 & 100 \\
\hline Ipswi & 86 & 100 & 100 & 0 & 0 & & & & & \\
\hline Kent & 372 & 100 & 100 & 99 & 100 & 25 & 100 & 100 & 96 & 100 \\
\hline L Kings & 480 & 100 & 100 & 0 & 0 & 62 & 100 & 100 & 0 & 0 \\
\hline Leeds & 434 & 100 & 100 & 100 & 100 & 41 & 100 & 100 & 100 & 98 \\
\hline Leic & 817 & 100 & 100 & 0 & 0 & 80 & 100 & 100 & 0 & 0 \\
\hline Middlbr & 231 & 100 & 100 & 0 & 0 & & & & & \\
\hline Newc & 191 & 100 & 100 & 0 & 0 & & & & & \\
\hline Norwch & 284 & 100 & 100 & 98 & 100 & 22 & 100 & 100 & 82 & 100 \\
\hline Wirral & 146 & 100 & 100 & 100 & 100 & 15 & 100 & 100 & 93 & 100 \\
\hline Wolve & 243 & 100 & 100 & 98 & 100 & 42 & 100 & 100 & 98 & 98 \\
\hline York & 132 & 100 & 100 & 100 & 98 & 16 & 100 & 100 & 100 & 100 \\
\hline \multicolumn{11}{|l|}{ N Ireland } \\
\hline Antrim & 107 & 100 & 100 & 100 & 100 & 13 & 100 & 100 & 100 & 100 \\
\hline Belfast & 155 & 100 & 100 & 100 & 100 & 16 & 100 & 100 & 100 & 100 \\
\hline Newry & 74 & 100 & 100 & 99 & 100 & 10 & 100 & 100 & 100 & 100 \\
\hline Ulster & 88 & 100 & 100 & 100 & 100 & & & & & \\
\hline West NI & 105 & 100 & 100 & 99 & 100 & & & & & \\
\hline \multicolumn{11}{|l|}{ Wales } \\
\hline Bangor & 63 & 100 & 0 & 0 & 0 & & & & & \\
\hline Swanse & 318 & 100 & 96 & 96 & 98 & 34 & 91 & 85 & 85 & 91 \\
\hline England & 9,462 & 100 & 93 & 40 & 31 & 894 & 100 & 93 & 44 & 37 \\
\hline N Ireland & 529 & 100 & 100 & 100 & 100 & 53 & 100 & 100 & 98 & 100 \\
\hline Wales & 381 & 100 & 80 & 80 & 82 & 34 & 91 & 85 & 85 & 91 \\
\hline $\mathrm{E}, \mathrm{W} \& \mathrm{NI}$ & 10,372 & 100 & 93 & 44 & 37 & 981 & 100 & 93 & 48 & 42 \\
\hline
\end{tabular}

Blank cells: centres with useable data for HD patients but not for PD patients 
blood loss); hyperparathyroidism and dialysis inadequacy.

Since the introduction of ESAs in the 1980s the management of renal anaemia has changed markedly, from the general acceptance of severe anaemia punctuated by intermittent blood transfusions, to the maintenance of acceptable $\mathrm{Hb}$ concentrations for patients with CKD. The understanding of what constitutes an acceptable $\mathrm{Hb}$ range has evolved with the published literature and is illustrated by the historic analyses in figures 7.18 and 7.35. These figures show a steady increase in $\mathrm{Hb}$ until the middle of the last decade followed by a steady fall during the last ten years. This change in trend followed the publication of the CHOIR and CREATE studies in 2006 which unexpectedly showed adverse outcomes from the physiological correction of haemoglobin with ESAs [6-7]. These findings were supported by the TREAT study in 2009 [8].

Haemoglobin outcomes were similar for both HD and PD patients with proportions of prevalent patients compliant with $\mathrm{Hb} 100-120 \mathrm{~g} / \mathrm{L}$ of 59\% and 57\% respectively. Prevalent HD patients had a higher median serum ferritin $(415 \mu \mathrm{g} / \mathrm{L}$ vs $295 \mu \mathrm{g} / \mathrm{L})$, a higher proportion of patients requiring ESAs (88\% vs $69 \%$ ) and a higher median ESA dose in those receiving ESAs (7,500 IU/week vs 4,000 IU/week) compared with prevalent PD patients.

As expected, a greater proportion of prevalent patients than incident patients attained $\mathrm{a} \mathrm{Hb} \geqslant 100 \mathrm{~g} / \mathrm{L}(80 \%$ vs $47 \%)$. Only $34 \%$ of late presenters achieved a $\mathrm{Hb}$ $\geqslant 100 \mathrm{~g} / \mathrm{L}$ suggesting that part of this difference is because there was less opportunity for anaemia to be treated with iron or ESAs. The fact that even in the early presenting incident group of patients only $51 \%$ achieved $\mathrm{Hb}$

\section{References}

1 Kidney Disease: Improving Global Outcomes (KDIGO) Anemia Work Group. KDIGO Clinical practice guideline for anemia in chronic kidney disease. Kidney Int Suppl. 2012;2:S279-S335

2 Kilger AS, et al. KDOQI US commentary on the 2012 KDIGO clinical practice guideline for anemia in CKD. Am J Kidney Dis. 2013; 62(5):849-859

3 Locatelli F, et al. Kidney Disease: Improving Global Outcomes guidelines on anaemia management in chronic kidney disease: a European Renal Best Practice position statement. Nephrol Dial Transplant 2013; 28:1346-1359

4 Renal Association Clinical Practice Guidelines Committee: Anaemia of CKD, 5th Edition. 2010 http://www.renal.org/docs/default-source/ default-document-library/anaemia-in-ckd-5th-edition.pdf?sfvrsn $=0$ $\geqslant 100 \mathrm{~g} / \mathrm{L}$ suggests that opportunity is only part of the explanation for incident patients. Alternative explanations include the fact that a number of patients commence dialysis at the time of an acute illness when acute anaemia is common.

The proportion of patients achieving a serum ferritin of $\geqslant 100 \mu \mathrm{g} / \mathrm{L}$ was $94 \%$ of $\mathrm{HD}$ patients and $88 \%$ of $\mathrm{PD}$ patients.

The NICE guideline on managing anaemia was published mid-way through the data collection period [5] and there are some fundamental differences between these and the previous Renal Association guideline, especially with respect to measurements of iron status. Specifically, the new NICE guidance recommends that percentage hypochromic red blood cells or reticulocyte haemoglobin are preferable markers of iron deficiency than serum ferritin or transferrin saturation. Renal centres will need to consider the incorporation of these changes into local guidelines as well as the need to ensure electronic collection of these data items. Assuming these recommendations are incorporated into the revised RA anaemia guidance, these additional iron indices will then need to be added to the UKRR dataset.

The analysis of ESA usage was limited by incomplete data returns. From the available data, $88 \%$ of HD patients and $69 \%$ of PD patients were receiving ESAs. The attainment of $\mathrm{Hb}$ targets correlated poorly with median ferritin and ESA usage.

There continued to be variation in concordance with anaemia guidelines between UK renal centres.

Conflicts of interest: the authors declare no conflicts of interest
5 National Institute for Health and Care Excellence (NICE). Chronic kidney disease: managing anaemia. 2015 nice.org.uk/guidance/ng8

6 Singh AK, et al. Correction of anemia with epoetin alfa in chronic kidney disease. N Engl J Med. 2006;355(20):2085-2098

7 Drüeke TB, et al. Normalization of hemoglobin level in patients with chronic kidney disease and anemia. N Engl J Med. 2006; 355(20):2071-2084

8 Pfeffer MA, et al. A trial of darbepoetin alfa in type 2 diabetes and chronic kidney disease. N Engl J Med. 2009;361(21):2019-2032 